\title{
A new regionalization of rainfall patterns based on wavelet transform information and hierarchical cluster analysis in northeastern Algeria
}

Bilel Zerouali ( $\boldsymbol{\sim}$ bilel.zerouali@yahoo.fr)

Universite Hassiba Benbouali de Chlef https://orcid.org/0000-0003-4735-9750

Mohamed Chettih

Zaki Abda

Mohamed Mesbah

Celso Augusto Guimarães santos

Reginaldo Moura Brasil Neto

\section{Research Article}

Keywords: cluster analysis, regionalization, rainfall, continuous wavelet analysis, drought, water resources, Algeria

Posted Date: May 26th, 2021

DOI: https://doi.org/10.21203/rs.3.rs-559269/v1

License: (1) This work is licensed under a Creative Commons Attribution 4.0 International License. Read Full License

Version of Record: A version of this preprint was published at Theoretical and Applied Climatology on January 7th, 2022. See the published version at https://doi.org/10.1007/s00704-021-03883-8. 


\title{
A new regionalization of rainfall patterns based on wavelet transform information and hierarchical cluster analysis in northeastern Algeria
}

\author{
${ }^{1}$ Bilel Zerouali, ${ }^{2}$ Mohamed Chettih, ${ }^{2}$ Zaki Abda, ${ }^{3}$ Mohamed Mesbah, ${ }^{4}$ Celso Augusto Guimarães Santos and \\ ${ }^{4}$ Reginaldo Moura Brasil Neto
}

(1) Plant Chemistry-Water-Energy Laboratory, Faculty of Civil Engineering and Architecture, Hassiba Benbouali, University of Chlef, B.P. 78C, Ouled Fares, 02180, Chlef, Algeria.,

(2) Research Laboratory of Water Resources, Soil and Environment, Department of Civil Engineering,
Faculty of Civil Engineering and Architecture, Amar Telidji University, P. O. Box 37.G, Laghouat 03000, Algeria

(3) Earth Sciences Faculty, University of Science and Technology Houari Boumediene, BP 32, 16311 Bab Ezzouar, Algeria

(4) Department of Civil Engineering and Environmental Engineering, Federal University of Paraíba, 58051-900 João Pessoa, Paraíba, Brazil

\author{
Corresponding Author's Name and Address \\ Zerouali Bilel \\ Email: bilel.zerouali@yahoo.fr \\ Plant Chemistry-Water-Energy Laboratory, Faculty of Civil Engineering and Architecture, Hassiba Benbouali, \\ University of Chlef, B.P. 78C, Ouled Fares, 02180, Chlef, Algeria., \\ ORCID ID: https://orcid.org/0000-0003-4735-9750
}

Funding: No funding was received for conducting this study

Conflicts of interest/Competing interests: The authors declare that there are no conflicts of interest regarding the publication of this paper.

Availability of data and material: The datasets generated during and/or analysed during the current study are available from the corresponding author on reasonable request.

Code availability: Not applicable

\section{Authors' contributions:}

Bilel Zerouali: Formal assessment, conceptualization, Writing - original draft preparation, supervision, and validation Mohamed Chettih: Framework of methodology, resources, writing and searching for bibliography

Zaki Abda: Methodology, processing data and drawing the figures

Mohamed Mesbah: Resources, Data collection and data analysis

Celso Augusto Guimarães Santos: Methodology; Writing - review and editing

Reginaldo Moura Brasil Neto: Writing - review and editing

Additional declarations for articles in life science journals that report the results of studies involving humans and/or animals: Not applicable.

Ethics approval: Not applicable

Consent to participate: Not applicable

Consent for publication: Not applicable 


\begin{abstract}
Due to its geographical location, Algeria is characterized by high spatiotemporal rainfall variability. In this study, data from 69 rain gauges located in representative humid, semiarid and arid Mediterranean basins in northeastern Algeria were analyzed from 1970-2007 on a monthly scale using continuous wavelet analysis and hierarchical cluster analysis with the aim of regionalizing the rainfall patterns. The analysis shows that northern Algeria (cluster \#1), which has a humid climate, is dominated by periodic annual fluctuations in the 8-16-month band. This mode explains most of the total variance, with a contribution between 25 and $60 \%$. In the cluster \#2 and cluster \#3 regions, the climate varies towards aridity (humid to arid from north to south), and the climate is dominated by long-term periodic phenomena characterizing multiannual fluctuations of 64-128 months to decadal periods greater than 128 months, which explains why the total cumulative contribution exceeds $50 \%$ of the total variance. In addition, the regional analysis of the isolated spectral bands of the 3-6-month (3 clusters), 8-16-month (3 clusters), and 1-3-year (4 clusters) scale-average variance revealed, globally and for the different regions, a long period of drought that was most pronounced during the 1970s, 1980s, and 1990s, whereas the wet years were marked by fluctuations that exceeded the $95 \%$ confidence level during the study period, with a very remarkable tendency towards wet conditions, particularly since the late 1990s. The obtained results can assist decision-makers in better sustainable development practices, especially in the fields of water resources, agriculture, and energy.
\end{abstract}

Keywords: cluster analysis; regionalization; rainfall; continuous wavelet analysis; drought; water resources; Algeria

\title{
1. Introduction
}

Understanding climate variability, climate change and global warming is essential for understanding world's water cycle. Understanding the various components water cycle's components has been the aim of a large body of studies on rainfall, flow, temperature, evaporation, infiltration (Mengistu et al., 2021; Dang et al., 2021; Pokharel et al., 2020; Nistor et al., 2020; Li et al, 2020; Bouabdelli et al, 2020; Zerouali et al., 2020; Machiwal et al., 2019; Pathak et al., 2017; Santos et al., 2018; Gocic and Trajkovic 2014; Duncan et al., 2013; Meddi et al., 2010) to be the key elements in designing and managing civil engineering structures, particularly studies on the precipitation component (Wolski et al., 2021; Martinez-Artigas et al., 2020; Zerouali et al., 2021; Machiwal et al., 2019; Merabti et al., 2018; Lazri 
and Ameur, 2018; Teodoro et al., 2015; Conway et al., 2010; Massei et al., 2011). Studies on rainfall are the most common compared to the other components; thus, the results of these works can help managers in decision-making processes in the field of water resources.

Some of the most common problems encountered by researchers in the fields of hydrology and meteorology are the lack and inadequacy of high-quality meteorological databases with long periods of observation and the lack of full coverage in measurements of hydroclimatic variables throughout river basins worldwide (McCabe et al., 2017). Therefore, researchers have developed and expanded tools, databases, mathematical and statistical theories to solve these problems (Hoffmann et al., 2004).

Climate regionalization is one of the most popular methods used in the decision-making process, particularly in cases of ungauged basins. It is the most commonly used method for reducing and assessing the uncertainties associated with predictions of climatic model outputs to provide more information for the understanding of atmospheric mechanisms, which can affect the climate of a region (Abadi et al., 2020). This technique consists of cutting or partitioning an area into homogeneous zones with similar climatic behaviors (Samantaray al., 2021; Cislaghi et al., 2020; Ullah et al., 2020; Abadi et al., 2020; Fathian et al., 2019; Santos et al., 2019; Roushangar et al., 2019; Mrad et al., 2019; Brito et al., 2017; Rau et al., 2017; Lyra et al., 2014). In addition to cluster analysis, multivariate statistical analysis (regional frequency analysis and self-organizing maps or SOMs) (Ullah et al., 2020; Wang and Yin 2019). Among such studies, Ali et al. (2019) identified homogeneous regions for drought characterization and monitoring based on the k-means classification algorithm and data from 52 rain gauges across Pakistan. The results identified nine groups and showed that a rain gauge located in one of the groups can be used for monitoring and characterizing drought in the whole region. Fathian et al. (2019) used a hybrid weighting-clustering approach for a regional frequency analysis of maximum 24-hour precipitation based on the statistical, geographic and climatic factors of 63 rain gauges in the Lake Urmia basin. The results indicated that the combination of these factors and the approaches that were used presented better values and increased the reliability of the extreme rainfall estimations. Roushangar et al. (2019) coupled a multiscale basic analysis of the maximal overlap discrete wavelet transform with a SOM algorithm for the classification of monthly rainfall based on data from 31 rain gauges in Iran. Based on verification of the silhouette coefficient index and physical analysis, the approach allowed the determination of homogeneous regions very well. García-Marín et al. (2015) applied a hybrid approach, combining multifractales analysis with the L-moments method for the delimitation of homogeneous regions based on data from 72 rain gauges 
in Andalusia (southern Spain). The results showed the success and effectiveness of the proposed approach for the clustering of homogeneous regions. Teodoro et al. (2015) applied the clustering method to analyze the spatiotemporal variability of monthly precipitation at 32 rain gauges located in Mato Grosso do Sul (Brazil). The analysis identified five homogeneous rainfall regions, and altitude was found to be one of the factors responsible for the spatiotemporal diversity of precipitation. Wang and Yin (2019) analyzed the variability and regionalization of precipitation based on a SOM network using a database of 1113 grid points covering the period from 1900-2014 on the Tibetan Plateau. The analysis suggested four clusters and that the SOM network satisfactorily represented the influences of atmospheric circulation systems. Rodriguez et al. (2016) improved the detection of homogeneous regions using entropy theory and the clustering method based on Euclidean distance in the Brazilian semiarid region. Based on the precipitation disorder index and latitude, the results revealed seven homogeneous areas in the Brazilian semiarid region. Brito et al. (2017) applied multivariate analysis on data from 100 rain gauges at a monthly scale in Rio de Janeiro (Brazil), and the analysis indicated six homogeneous regions. According to the authors, the obtained results can help decision-makers formulate public policies for better risk and natural disaster management and future investments. Machiwal et al. (2019) analyzed rainfall regionalization and the factors that affect it using principal component and hierarchical cluster analyses in dry regions in western India based on data from 62 rain gauges from 1957-2011. The method succeeded in separating regions with low and high rainfall, and the results could be essential for planners formulating strategies for hydraulic and civil engineering structure management. In Alagoas State, northeastern Brazil, Lyra et al. (2014) used the hierarchical cluster method to analyze spatiotemporal rainfall variability. The results indicated a uniform spatial rainfall distribution with strong gradients from north to south and from the coast to the continent due to the physiography of the study area and weather systems.

Additionally, all emission scenarios listed in the reports of the Intergovernmental Panel on Climate Change (IPCC 2014) indicate that warming over the next two decades will increase by approximately $0.2^{\circ} \mathrm{C}$ per decade. The IPCC documented that many semiarid regions, such as the Mediterranean region, western North America, Southern Africa and northeast South America, particularly Brazil, will suffer from a lack of water resources resulting from climate change (Zerouali et al., 2018). Spatiotemporal drought was analyzed between 1960 and 2010 on the plains of northwestern Algeria (Cheliff watershed) using the standardized precipitation index (Achour et al., 2020). The analysis indicated that a severe drought affected the region, and the severity and duration of the drought decreased in the eastern part of the region. Hallouz et al. (2020) assessed meteorological drought during the period from 1972-2012 in the 
semiarid climate region of northwestern Algeria. The drought analysis revealed that the rain gauges in the western region recorded the largest durations of dry sequences, and the highest values of consecutive dry days were recorded in February. Using copula analysis on data from 194 rain gauges located in northern Algeria for drought event identification, the severity-area-frequency and severity-duration-frequency curves indicated that the western part of the region is the most sensitive to dangerous and severe droughts of short durations and high probabilities of exceedance (Mellak and Souag-Gamane 2020). Based on rain gauges in northern Algeria, Zerouali et al. (2020) used relatively new hybrid methods for the detection of changes points and trends during the period from 1920-2011. The results revealed a decline in the rainfall amount beginning in the 1970s in the western part of the region. The authors also concluded that low-frequency phenomena (multiannual to interdecadal modes of variability) can contribute to hiding long-term trends in the studied rainfall time series. In the Seybouse basin (Algeria), Khezazna et al. (2017) observed a long period of drought with significant interannual variability during the period from 1970 to 1999 , followed by an increase in rainfall beginning in 2001. Using the Köppen-Geiger climate classification scheme, Zerouali et al. (2019) analyzed climate change in Algeria from 1951 to 2098 based on representative concentration pathways (RCP4.5 and RCP8.5) and CORDEX-Africa regional climate models. The authors revealed a shift in the rate of climate zone areas from 1951 to 2005 , with an increase in the surface area of the desert zone. The RCP8.5 scenario indicated an increase in the desert climate from 2045 to 2098. Based on the RCP4.5 and RCP8.5 scenarios, Bouabdelli et al. (2020) analyzed the impact of climate change on hydrological drought risk recurrence in northwestern Algeria using coupling methods among bivariate frequency analysis, RCP4.5, RCP8.5 and GR2M. The results indicated that the future hydrological drought risk could increase due to decreases in the return periods of drought in all study areas. In northern Algeria, rainfall variability was analyzed using field observations and regional model simulations by Taibi et al. (2019). The simulation analyses revealed a downward trend starting in 1970; similarly, future climate projections indicate declines in rainfall in the 2021-2050 and 2070-2099 periods.

Studies in the fields of statistical hydrology, agriculture and natural resource management specifically related to Algeria are not sufficient and cover only short periods in relation to the natural resources available. In the climate context, climate models project that future rainfall in Algeria will be less frequent but more intense with high variability in its spatiotemporal distribution, while droughts will be more frequent and longer (Boucherf, 2004). In the context of 
rainfall regionalization and spatiotemporal analysis in Algeria, studies have been carried out by Rata et al. (2020), Mrad et al. (2019), Lazri and Ameur (2018), Merabti et al. (2018a,b), Mokdad and Haddad (2017).

We could not find any study regarding regional analyses of rainfall behavior over Algeria in terms of variability patterns and rainfall changes using statistical methods coupled with a multiscale spectral analysis approach. Thus, this study proposes a new method for the clustering of different modes of rainfall variability and climate trends in the time-frequency domain in the eastern part of northern Algeria. The analyses were based on data from 69 rain gauges for the period from 1970-2007 at a monthly scale and were conducted by combining the ascending hierarchical clustering method with Ward's method and the Euclidean distance algorithm, considering the global wavelet spectra and the scale-average variance time series resulting from the continuous wavelet transform.

\section{Study Area}

The study region is the eastern part of northern Algeria, which covers an area exceeding $110000 \mathrm{~km}^{2}$, between $3^{\circ} 15^{\prime \prime}$ $\mathrm{E}$ and $8^{\circ} 70^{\prime \prime} \mathrm{E}$ and from $34^{\circ} 30^{\prime \prime} \mathrm{N}$ to $37^{\circ} 15^{\prime \prime} \mathrm{N}$. It extends from the Mediterranean coast and the highlands of the Tell Atlas mountains in the north to the Saharan Atlas mountains and the southern plains, bordering the Sahara Desert to the south (Merabti et al., 2018a,b). Northern Algeria includes five hydrographic basin, and each one includes several hydrological basin. The area contains three distinct hydrographic groups: ID 01 (the Seybouse-Mellégue and the Constantine highlands), ID 02 (Chott Hodna-Soummam) and ID 05 (Chott Melrhir) (Fig. 1a). The study area includes nine basins (ID 02: Coastal Algeries, ID 03: Coastal Constantine, ID 05: Chott Hodna, ID 06: Chott ElMeghir, ID 07: High Plan Constantinoise, ID 10: Kebi ElRhimel, ID 12: Medjreda, ID 14: Seybouse and ID 15: Soummam) (Fig. 1b). The region contains mountains of various heights (low, medium and high), high plains, high plateaus and the Tell Atlas mountain range. These mountains are cut by deep gorges with large, intercalated bowls. To the south, the highlands are delimited by the chains of the Saharan Atlas mountains and by the Aurès massif, with some peaks higher than 2300 m above sea level (Fig. 1) (Merabti et al., 2018a, b). In northern Algeria, rainfall is very variable in space and time, ranging from 148 to $1300 \mathrm{~mm}$ per year. Several factors contribute to this distribution, which are related to the relief and orientation of the basins. Northwest winds meet the Iberian mountain chains (Spain), and dry winds from the Moroccan Atlas mountains arrive in northern Algeria and are then recharged in the Mediterranean, contributing to heavy rainfall in the northern Tell Atlas mountains. This decrease in rainfall from north to south is superimposed on 
an increase in rainfall from west to east (depending on the longitude). This pattern is particular to Algeria (Fig. 1b, c) (Meddour 2010; Zerouali et al., 2018; Merabti et al., 2018a,b; Meddi et al., 2010).

\section{Materials and Methods}

\section{1. Rainfall data}

The rainfall database used in our study includes more than 100 rain gauges, from which 69 rain-gauges (stations) were selected (Fig. 1b) to provide the monthly time series data from January 1970 to December 2007; these gauges were selected because they have the longest time series and less than 5\% missing data (Table 1 and Fig. 2).

The gaps due to missing data were filled using the least square method based on neighboring gauges. The database was obtained from the National Agency of Water Resources (ANRH) of Algeria. Table 1 provides information about the identification number (ID), geographic characteristics and average annual rainfall of the 69 rain gauges used in the analyses.

\section{2. Continuous wavelet transform}

In this study, wavelet analysis using the Morlet mother wavelet was applied to all 69 monthly precipitation time series available in the study area. For each precipitation time series, the global spectra and scale-average variance were evaluated at multiple time scales. The continuous wavelet transform (CWT) is a tool that allows the study of the spectral composition of nonstationary signals (Torrence and Compo, 1998; Santos et al., 2001; Grinsted et al., 2004; Massei et al., 2011) and provides representation of the variance time evolution of a time series (Labat, 2005). One of the main arguments in favor of wavelet analysis is that the stationarity of the time series is not a prerequisite (Nakken, 1999). In addition, the CWT is used to understand changes in the low- and high-frequency periodicities of a time series in the time-frequency domain. According to Truche (2010), at low frequencies, the CWT is precise in frequency but less precise in time. Conversely, at high frequencies, the CWT is precise in time and less precise in frequency. This characteristic translates the adaptation of the CWT to the studied signal, unlike the window Fourier transform, which retains a constant resolution in its analysis regardless of the frequency analyzed.

For a discrete time series consisting of $X_{n}$ values, the CWT $W_{n}(s)$ is defined by the convolution of $X_{n}$ with a wavelet $\Psi_{0}(\eta)$ and consists of a complex wave modulated by a Gaussian function $W_{n}(s)$, which is represented as follows: 


$$
W_{n}(s)=\sqrt{\frac{\delta t}{s} \sum_{n=1}^{N} x_{n^{\prime}}} \Psi^{*}\left[\left(n^{\prime}-n\right) \frac{\delta t}{s}\right]
$$

Further, $\Psi_{0}(\eta)$ is given by the following equation:

$$
\Psi_{0}(\eta)=\pi^{-0.25} e^{i \omega_{0} \eta} e^{-0.5 \eta^{2}}
$$

where $(*)$ is the complex conjugate; $s$ is the wavelet scale parameter related to the frequency; $\eta$ is the translation or localization factor related to the time (an adimensional parameter); $\delta t$ is the time interval between $X_{n}$ and $X_{n-1} ; \omega_{0}$ is an adimensional frequency, In order to satisfy the eligibility condition and select the right choice for the Morlet mother wavelet, 6 is the optimal choice for the value of $\omega_{0}$; this value provides a good experimental balance between the time and frequency locations.

According to Anctil and Pelletier (2011), calculating an average power spectrum using bands of periods allows the clear illustration of the differences in the frequency distribution and temporal evolution of the variance. The spectrum for a selected band consists of the weighted sum of the power spectrum between two scales, $s_{1}$ and $s_{2}$, defined by the user (Torrence and Compo, 1998; Santos et al., 2001; Grinsted et al., 2004; Santos et al., 2013). The power spectrum or scale-average variance is calculated by the following expression:

$$
\bar{W}^{2}=\frac{\delta_{j} \delta_{t}}{C_{\delta}} \sum_{j=j 1}^{j 2} \frac{\left|W_{n}^{X}\left(s_{j}\right)\right|^{2}}{s_{j}}
$$

where $\delta_{j}$ is a factor of the frequency resolution (set to 0.1 ), and $C_{\delta}$ is a reconstruction factor for the case of the Morlet mother wavelet and is set to 0.776 . To define a nonzero interval, the value of $j_{1}$ must always be less than that of $j_{2}$. According to Santos and de Morais (2013), the global wavelet spectra provide an unbiased and consistent estimation of the true power spectrum of the time series, it is useful in summarizing the temporal variability in a region

\section{2. 2 Hierarchical cluster analysis}

In this work, Ward's method of linkage between clusters, based on Euclidean distance as a dissimilarity metric, was used. Thus, we developed analyses considering the behavior of the global spectra and variance time series for the 69 rain gauges. In the case of the global wavelet spectra, cluster analysis was performed only once. In the case of the variance time series, scales of $0.3-0.6$ months, 8-16 months and 1-3 years were used to group the time series into different clusters. The ascending hierarchical classification (AHC) is one of the techniques that used for providing a set of partitions in a series ' $\mathrm{W}$ ' in increasingly broad classes, wherein each group or partition has homogeneous or similar characteristics. The euclidean distance, as its name implies, computes the 
distance between points, then the Ward's method aims at grouping points that are ri,j distance away into a cluster, so that, when adding new points to this cluster, the distance between this cluster and other clusters, changes at little as possible (Ward, 1963). Ward's method is given by the following expression (Everitt and Dunn, 1991; Wilks, 1995):

$$
d_{e}=\sqrt{\sum_{j=1}^{n}\left(P_{p, j}-P_{k, j}\right)^{2}}
$$

Where $d_{e}$ is the Euclidean distance between the metrics, and $P_{p, j}$ and $P_{k, j}$ indicate the $j$-th statistic calculated for rain gauges $\mathrm{p}$ and $\mathrm{k}$, respectively. According to Brito et al. (2017), the dendrogramic distance between the clusters ( $\left.\mathrm{d}_{\mathrm{c}}\right)$ is calculated from the following equation:

$$
d_{c}=\sum_{i=1}^{n} x_{i}^{2}-\frac{1}{n}\left(\sum x_{i}\right)^{2}
$$

Where $n$ is the number of rain gauges and $\mathrm{x}_{\mathrm{i}}$ is the $\mathrm{i}$-th rain gauge in the cluster. The analyses were performed using the XLSTAT 2014.5.01 demo version developed by Addinsoft. More details on the AHC can be found in Everitt and Dunn (1991), Wilks (1995) Lyra et al. (2014), Brito et al. (2017), Fazel et al. (2017) and Santos et al. (2019).

\section{Results and Discussion}

\section{1 Continuous wavelet analysis}

To characterize periodic, stationary and nonstationary phenomena, identify the main modes of rainfall variability and their percent contributions to the total variance, and identify dry and wet periods in the monthly rainfall time series (Fig. 2), the continuous wavelet transform (CWT) was applied (Fig. 3). The data is 38 years long, and the cone of influence (COI), at period 96 months, is already 12 years large on each side, so that's 24 years of data inside the COI. This leaves only 14 years of data. Therefore, it is easy to determine whether the power of the variance in different scales, from short- to long-term, is stable over the observation period.

The continuous wavelet spectra of rainfall are represented in terms of two-dimensional time-frequency figures (Fig. 3). The rainfall spectra of the study region show, as a first observation, that the spectral responses differ from one rain gauge to another, and globally, the spectra show stationary fluctuations that are well-distributed at different time scales. Annual fluctuations presenting strong coefficients wavelet coefficients are a measure of they are not constant through time for those stations (Fig. 3). Stationary and non-stationary phenomena resulting from the CWT is a marker of trends and change points in rainfall time series. 
AHC is the technique that enables to achieve the objective of this study, which is a regionalization of rainfall patterns over Northern Algeria at different modes of variability and trends. The dendrograms in Figure 4 represent the homogeneous regions based on the AHC for the GWS (4a), 3-6-month (4b), 8-16-month (4c) and 1-3-year (4d) scaleaverage variance time series based on monthly rainfall over northeastern Algeria. Variance decomposition for optimal classifications obtained from automatically computing of Xlstat have been shown in Table 2

\section{2 Spatial analysis of rainfall patterns}

Based on the AHC, three groups of homogeneous modes of variability were identified over the study region (Figs. 4a, 5). This diversity may be due to the complexity of the study region (distance from the sea, geomorphology, geology, climate, relief and other characteristics). Group 1 (G1) includes the largest number of rain gauges, exceeding $50 \%$ of the total number of gauges (39 stations) (Fig. 6a), which are distributed over the northern part of the area near the Mediterranean Sea at altitudes between 40 and $800 \mathrm{~m}$ with some peak ridges reaching $2300 \mathrm{~m}$. This region is characterized by a humid and subhumid climate with average annual precipitation reaching $1700 \mathrm{~mm}$ according to the recent map by Merabti et al. (2018a,b). The G1 group includes the coastal Algiers (02), coastal Constantine (03), Soummam (15), Kebir Rhumel (10) and Saybouse (14) basins (Fig. 1b), covering an area approximately equal to 33\% of the study area (Fig. 6a). The area of each group was calculated using the area of each basin as a unit of measurement (Fig. 1b).

Group 2 (G2) is located in the interior of the study area, which has a subhumid and semiarid climate in which the precipitation is between $250-550 \mathrm{~mm}$ per year. This group includes only nine rain gauges (13\% of the total number of gauges) (Fig. 6b), the lowest number of rain gauges of any group, and extends over an area comprising $30 \%$ of the entire study area (Fig. 6a). In addition, the G2 rain gauges are distributed in sparse manner over the basins, i.e., the Chott Hodna (05) and Kebir Rhumel (10) basins, where altitudes vary between 400 and 1000 m (Fig. 1a).

In the third group (G3), the rain gauges are uniformly distributed across the basins, i.e., Chott El-Melghir (06), the high Constantine plains (07), the Medjerda (12) and Chott Hodna (05). G3 occupies the southern part of the study region near the Sahara basin, with a surface area contribution equal to $42 \%$ of the total area (Fig. 6a) and altitudes between 800 and $2300 \mathrm{~m}$, which contributed to the homogeneity of this group, with the exception of a few peak ridges below 800 m observed in the Medjerda and Chott Hodna basins. G3 is completely subject to a semiarid climate in 
which rainfall reaches only $300 \mathrm{~mm}$ per year and includes $30 \%$ of the total number of rain gauges (21 gauges) (Fig. 6b) with four rain gauges located near the border with Tunisia.

The GWS time series of G1, G2 and G3 are shown in detail in Figures 7a, 7b and 7c, respectively. Figure 7d illustrates the time series from a representative rain gauge of each group: G1 (blue), G2 (red) and G3 (green), with the $5 \%$ significance level represented by the light blue lines (Fig. 7d). It is worth noting that the three $95 \%$ confidence curves are stacked on top of each other with slightly different values. In addition, the percent contributions of the selected seven modes of variability, i.e., 3-6-month, 8-16-month, 1-3-year, 2-4-year, 3-6-year, 6-8-year and 8-12year, to the total variance were calculated from the GWS (Fig. 7) for each group, i.e., G1 (Fig. 8a), G2 (Fig. 8b) and G3 (Fig. 8c). As first observation, the sum of the contribution higher than $100 \%$, because some variance because some mode of variability are in common with each other as (1-3 year with 2-4 year and 2-4 with 3-6 year). Globally, the results obtained from the analyses show a heterogeneous rainfall pattern according to the modes of variability (frequency space), which agrees with the results obtained for western and eastern Algeria (Khedimallah et al., 2020), Tunisia (Jemai et al., 2017) and Morocco (Zamrane et al., 2016).

In the short term, the CWT (Fig. 3) and GWS of the G1 precipitation (Fig. 7a) reveal the existence of nonstationary structures, where the seasonal periodicity intervals (3-6 months) are slightly structured and have low percent contributions between 7 and 15\% (Figs. 8a, 9). By contrast, in the medium term (8-16 month to 1-3 year), the analysis indicates the dominance of the annual periodic phenomena with significant power at a confidence level of 95\%, which are expressed by sharp peaks compared to the other modes of variability (Fig. 7a, d). These annual fluctuations explain most of the total variance, with a contribution between 25 and 60\% (Figs. 8a, 9). On the interannual scale, the 1-3-year mode of variability appears to be clearly visible between 1975 and 1984 and from 1999 to 2004 (Figs. 3a, 7) with a rupture in the blue color that reveals the disturbance in the continuity. The dominance of 1-year and 1-3-year fluctuations was also observed in the Sebaou River basin (northern central Algeria) (Zerouali et al. 2018). This high variability can be explained by the effects of the Mediterranean effects on rainfall processes. A transition to multiannual modes of variability (2-4 years and 3-6 years) was easily observed, for example, in the rain gauges 021703 and 030102 of G1 (Figs. 3b, 7). The various fluctuations cited above explain why the contribution does not exceed $25 \%$ of the total variance (Figs. 7a, $8 \mathrm{a}$ and 9). The decadal fluctuations are visible and but it present just a contribution of $6 \%$ (Fig. 7a, 8a and 9). 
Analysis of the GWS of G2 represented in Figure 7b, shows that the mode of variability of Cluster 2's wavelet spectra are very close to those of cluster 1 with visibility of 128 month mode of variability (Fig 7b,d). The short-term seasonal fluctuations 3-6 months in G2 show weak amplification in the spectrum, with a low contribution of less than $14 \%$ to the total variance (Figs. $8 \mathrm{~b}, 9)$. The annual periodic phenomena (8-16 months) are visible on the GWS (Fig. 8b) and are expressed by a less intense amplification compared to those of G1 in the CWT and GWS. The annual mode contributes between 15 and $28 \%$ to the total variance (Figs. 8b, 9). Compared with the annual mode, the multiannual variability modes of 1-3 years (16-32 months) and 3-6 years (32-64 months) show some amplifications, with a maximum cumulative contribution reaching 55\% (Figs. $7 \mathrm{~b}, 8 \mathrm{~b}$ and 9), and these amplifications are easily observed after 1986 (Fig. 3c,d). The 64-128-month scales, characterizing the multiannual components, show obvious amplifications in the GWS spectra, particularly for the rain gauge 030204. This mode is the most dominant for this group (G2) (Fig. 6b) and explains more than $25 \%$ of the variance (Figs. 7b, d, 8b, and 9).

For G3, the GWS (Fig. 7c, d) highlights the seasonal (3-6-month), annual (8-16-month) and interannual (1632-month) components that temporally localised, isolated events, revealing singularities (no stationary) (Fig. 3e,f). The maximum contribution of the different modes of variability does not exceed $28 \%$ (Figs. 8c, 9).

At small scales, the GWS of G3, which is temporally subjected to semiarid and arid climates, highlights highfrequency processes, the amplifications of which are clearly visible (Figs. 7c, d). The contribution of this mode reaches a maximum of $21 \%$ of the total variance (Fig. 8c, 9). The spectra reveal the presence of some large-scale processes that are more or less well-localized over time. A multiannual process of 32-64 months (3-6 years) (Fig. 6c) localized between 1978 and 2002. This mode gradually changes to a decadal fluctuation, which remains insignificant outside the COI (Fig. 3e). The 32-64-month mode shows a contribution to the total variance between 12 and $27 \%$ (Figs. 8c, 9). The rainfall of G3 indicates that the annual processes (8-16 months) are slightly structured (Figs. 3e, f) and less attenuated in the GWS than other components are (Figs. 7c, d); when compared with the other components that have lower temporal variabilities, the annual processes disappear very quickly. The annual mode of G3 indicates the lowest contribution compared to the annual modes of G1 and G2, with the maximum contribution not exceeding $23 \%$ (Figs. 8c, 9). Overall, for G3, the analysis revealed the existence of nonstationary structures in the medium to long term, which the most spectacular is that of the 64-128-month mode. 
From these results, we can conclude that the northern part of Algeria (G1) is dominated by annual periodic fluctuations in rainfall of $8-16$ months. This indicates that the increase in average rainfall due to the humid climate may be responsible for the formation of periodic components, particularly annual fluctuations (Zerouali et al., 2018). G2 is dominated by periodic interannual fluctuations (1-3 years and 2-4 years), and G3 is characterized by interannual and decadal fluctuations (8-12 years). According to the obtained analyses, when the climate of a region tends towards aridity, the climate will be dominated by periodic long-term phenomena (multiannual to decadal). In contrast, humid and subhumid climate regions will be dominated by seasonal, annual and interannual fluctuations that explain shortto medium-term processes. Based on long-term and quality-controlled rainfall time series in southwestern Europe (Peña-Angulo et al., 2020) and northern Algeria (Zerouali et al., 2020), the authors of previous studies found that in

the absence of statistically significant long-term trends (increasing/decreasing) in rainfall time series, except for over short periods, the interannual to interdecadal mode of variability detected in the analyses can contribute to hiding longterm trends in rainfall time series.

This finding is important for the detection of change points and trends in studies of hydrology and earth science. The diversity of rainfall patterns around the study area can be associated with and affected by longitude, explaining a decline in rainfall from north to south, particularly in Algeria, which explains Figures 1b and c (Merabti et al., 2018a,b; Meddour, 2010; Meddi et al., t2010). In addition, according to Mathbout et al. (2019), the distance from the sea (longitude, in the present case) and latitude of a given location might be the most important factors that affect the variations and spatial distribution of rainfall across the Mediterranean basin. The results obtained from the analysis indicate that each region of the study area is characterized by a climate stage (humid, subhumid, semiarid and arid), each climate stage is characterized by a specific mode of variability, and longitude is one of the important factors influencing this diversity.

\section{3 Spatial analysis of trends and variability at different time scales}

In this section, the seasonal (3-6-month), annual (8-16-month) and multiannual (1-3-year) components from the 69 CWTs (Fig. 3) were isolated and extracted to examine their variance and analyze their climatic behavior. According to the literature, there is only a single study, by Santos et al. (2018), that combined the wavelet spectra of the scaleaverage variance of monthly average flows from eight stations and a hierarchical cluster analysis in the Black Sea 
region (Turkey). The method succeeded in determining similar hydrological regions and extracting dramatic fluctuations.

Spatial analysis by the AHC of seasonal components (3-6 months) indicates the existence of three groups of regions with homogeneous climatic behavior (Fig. 10). G1 comprises $42 \%$ of the rain gauges (29 gauges) (Fig. 6b), which are well-distributed over the northwestern part of the region near the Mediterranean Sea with a humid and subhumid climate. The G1 group includes the following basins: coastal Algeries (\#02), half of the coastal Constantine (\#03), and Soummam (\#15) (Fig. 1b), covering an area of less than 33\% of the study area (Fig. 6a). In contrast, G2 occupies the northeastern part of the study area and contains 11 rain gauges (16\%), which are located in the second half of the Constantine coastal area (\#03) and in the Seybouse (\#14) basin, which together occupy an area equal to $15 \%$ of the study area (Figs. 1b, 10a). G3 extends over more than $65 \%$ of the study region and contains $42 \%$ of the rain gauges (29 gauges) (Fig. 6b). This group is distributed over the basins of Chott Hodna (\#05), Chott Melghir (\#06), the Constantine high plains (\#07), Medjerda (\#12) and southern Kebir Rhimel (\#10) (Fig. 1b).

Cluster analysis of the annual components (8-16 months) also revealed three groups of homogeneous regions, more or less spatially sparse for the G1 rain gauges (25 rain gauges or 37\%) (Fig. 6b), distributed in the coastal Algeries (02), Soummam (15), Chott Hodna (05) and Kebir Rhimel (10) (Fig. 10b) with a combined area exceeding $40 \%$ (Fig. 6a). G2 included only 22 rain gauges (33\%) (Fig. 6b), extending over $43 \%$ of the study area (Fig. 6a). In addition, the rain gauges in this group are well-distributed over the following basins: Chott Melghir (06), the high Constantine plains (07), Medjerda (12) and Kebir Rhumel (10) (Fig. 1b, 10b). G3 shows that the rain gauges (22\% of the gauges) are uniformly distributed on the basin scale, and this group contains the following basins(Fig. 10b): the Constantine coastal areas (03), Soummam (15) and Seybouse (14). The G3 group occupies 22\% of the area (Fig. 6b).

Hierarchical clustering of the multiannual components (1-3 years) showed four different climatic behavior groups or heterogeneous groups, as shown in Fig. 10c. The G1 group agglomerates 24 rain gauges as follows: 2 rain gauges in coastal Algeries, 15 rain gauges in Soummam and 7 rain gauges in the high Constantine plains (Figs. 1b, 10c), with a combined area exceeding $30 \%$ of the total study area. The G2 group is located in the northern part of the coastal Constantine (3 gauges) and Seybouse (14 gauges) basins (Fig. 10c). However, the G3 rain gauges are sparsely distributed in the following basins: Medjerda (12 gauges) and Kebir Rhimel (10 gauges). G4 included $20 \%$ of the rain 
gauges, which are distributed in the Chott Melghir (6 gauges) basin and in the high Constantine plains (7 gauges) (Figs. $6 \mathrm{~b}, 10 \mathrm{c})$.

\subsubsection{Rainfall variability at the temporal scale of 3-6 months}

At the seasonal scale, in the 3-6-month band (Fig. 13), great variability in the variance over time is noted, with spectacular peaks exceeding the significance level for G2 and G3 (Fig. 11b, c). In contrast, G1 immediately shows a downward trend. This downward trend is well-illustrated during the 1976-1980 and 1983-1993 periods and has been increasing from 1993 (Fig. 11a, d).

\section{3. 2 Rainfall variability at the temporal scale of 8-16 months}

The global analysis of the scale-average variance of the annual components for the 8-16-month band (Fig. 12) of the three groups resulting from the cluster method shows exceptionally rainy years exceeding the significance level between 1972-1974, 1980-1984, and 2002-2006. In contrast, dry periods are marked by low variability, below the significance level, between 1974-1980 and 1984-2002. This period of drought is well-established, particularly in the region including G2 (Fig. 12c, d); it has also been observed in the Mediterranean basin (Zerouali et al., 2020; Khezazna, et al., 2017; Philandras et al., 2011; Piccarreta et al., 2013; Nouaceur and Murărescu, 2016). According to Hasanean (2004), the negative trends of rainfall in the western Mediterranean coincide with subtropical anticyclonic trends, which, since 1970, have been known to increase pressure.

\section{3. 3 Rainfall variability at the temporal scale of 1-3-years}

At the interannual scale, for the 1-3-year band (Fig. 13), large fluctuations in variance were observed, but they were below the confidence level of 95\% (Fig. 14e). G1 shows low variability in variance between 1970-1972, 1974-1993 and 1995-1998 (Fig. 13a), expressed as very remarkable dry periods. G2 and G3 (Fig. 13b, c) also show similar fluctuations to G1 (Fig. 13a) with a wet period starting from the late 1990s, which corroborates the results and information obtained from spectral 3-6-month bands. G4 revealed (Fig. 13d) the lowest variability in the variance, indicating that this region is the region that is most affected by droughts, except for a few severe peaks characterizing wet years in 1990 and 1996. These observed trends (Figs. 11, 12,13) concern all rain gauges in northern Algeria and the Mediterranean basin, which confirms the existence of significant rainfall deficits in the 1970s, 1980s and 1990s (Bouabdelli et al., 2020; Khedimallah et al., 2020; Zerouali et al., 2020; Peña-Angulo et al., 2019; Jemai et al., 2018; 
Taibi et al., 2017, 2019; Mrad et al., 2019; Zerouali et al., 2018; Caloiero et al., 2018; Merabti et al., 2018a,b; Zeroual et al., 2017; Da Silva et al., 2015; Gocic and Trajkovic, 2014; Hamlaoui-Moulai et al., 2013; Meddi et al., 2010).

Based on 233 daily rainfall time series, Mathbout et al. (2019) observed a decrease in rainfall over the western Mediterranean, especially in Maghreb countries, France, Italy and Spain, that might be associated with shift towards positive North Atlantic Oscillation (NAO+), and the authors concluded that the NAO could play an essential role in modulating Mediterranean rainfall. In the Mediterranean region, López-Moreno et al. (2011) observed that the different winter modes in the majority of the mountain areas were closely related to the NAO index, which may lead to a greater frequency of warm and dry winters. Massei et al., (2017) showed that there is a time scale dependence of links between atmospheric circulation patterns (such as NAO) and hydroclimate series in Seine river catchment, France. Using continuous wavelet analysis, Khedimallah et al. (2020) found that the rainfall of the Cheliff and Medjerda basins (Algeria) and the NAO index are strongly correlated, with correlations ranging from 60 to $84 \%$. The analysis by the cross time-frequency techniques used by Zerouali et al. (2018) shows good consistency between the NAO and precipitation of northern central Algeria, especially in the second half of the period from 1972-2010, corresponding to the period associated with a dry trend starting in 1980. Munoz-Diaz and Rodrigo (2003) found an upward trend in rainfall amounts corresponding to the negative phase of the NAO and a downward trend corresponding to the positive phase, with more extremes associated with the negative or harmful phase of the NAO. Xoplaki et al. (2004) found that the positive phase of the NAO recorded after 1975 corresponds to a period of rainfall deficit for all the plains of the Iberian Peninsula. In the region of Abruzzo (Italy), Vergni et al. (2016) observed that the positive NOA is responsible in the main cases for negative trends in rainfall, while the negative NAO phase plays the opposite role. Sun et al. (2014) showed that the southern part of Europe has become drier since 1980, which is due to the positive phase of the NAO. According to Massei et al. (2011), the periods of strong NAO/rainfall consistency over Europe generally tend to increase between 1950 and 2000. This general strengthening of the coherence between the two fluctuations, beginning in the 1990s, appears at a recognized, strongly positive NAO phase period. It therefore results in similar oscillations on scales of approximately 1 year, 2-3 years and 5-7 years. This explains why the NAO is one of the main factors responsible for drought occurrence in northern Algeria and the Mediterranean basin (Khedimallah et al., 2020; Mathbout et al., 2019; Mühlbauer et al., 2016; Hamlaoui et al., 2013, Ouachani et al., 2013, Zerouali et al., 2018; Taibi et al., 2017; Zeroual et al., 2017; Meddi et al., 2010). 


\section{Conclusions}

In this work, efforts were made, using a large amount of information and data resulting from continuous wavelet analyses, to develop a regional model of climatic rainfall behavior at different frequency and time scales. The results led to the following conclusions:

On the frequency level (Fig. 5a and Fig. 7):

- The northeastern portion of Algeria (G1) is predominantly characterized by periodic annual precipitation fluctuations at the 8-16-month band, which presents the most significant contribution to the region's precipitation variance, with a contribution between 25 and $60 \%$. The appearance of this mode is due to high rainfall variability (rainy character) of the humid climate.

- According to observations obtained in G2, where the climate tends towards aridity (from north to south), the region is dominated by periodic long-term phenomena (interannual up to decennial) or by phenomena seen in the spectral 64128-month bands and the bands greater than 128 months, which have a total cumulative contribution that exceeds $50 \%$ of the total variance. This diversity may be due to the complexity of the study region (distance from the sea, geomorphology, geology, climate and relief).

- For G3, the analysis revealed the existence of nonstationary structures in the medium to long term, which the most spectacular is that of the 64-128-month.

On the temporal level (Fig. 5 and Figs. 10, 11, 12 and 13):

- The results of the three isolated components and the different homogeneous regions highlighted the alternation of wet and dry years, in which the years of drought were more pronounced during the decades of the 1970s, 1980s and 1990s, whereas the wet years were more prominent during a few years of the study period and, particularly, during the decade of the 2000s. The results obtained from the drought analysis are consistent with those of other works carried out in Algeria and the Mediterranean regions for similar periods, which are mentioned above.

This study site, which is this study comprises the northeastern region of Algeria, should subsequently be extended to the entirety of Algeria. In fact, each region in Algeria will face specific problems; this is why separate observations were presented and reported for each region or site, which can help in finding a single model that is applicable to all sites. The information gathered from this study will set up a support base for decisions and will, in fact, allow a dialogue between researchers and managers from different sectors (mobilization of water resources, agriculture, energy, environment, construction and other sectors). Finally, our future research perspectives and 
objectives will be oriented towards analyses of the existence of possible relationships in the time-scale space between the NAO and the precipitation trends observed in this study and toward using other mathematical cross-analysis techniques.

\section{Acknowledgments}

The authors gratefully thank the Directorate General for Scientific Research and Technological Development of Algeria and the Brazilian Agency for the Improvement of Higher Education (Coordenação de Aperfeiçoamento de Pessoal de Nível Superior-CAPES) for supporting this research. The authors thank all the engineers of the National Agency of Water Resources (ANRH), who provided us with necessary data. This and all my works are dedicated to the memory of my beloved wonderful mom and darling sister. Will they forever remain in my soul.

\section{References}

Abadi, A. M., Rowe, C. M., \& Andrade, M. 2020. "Climate regionalization in Bolivia: A combination of nonhierarchical and consensus clustering analyses based on precipitation and temperature". Int J Climatol https://doi.org/10.1002/joc.6464

Achour, K., Meddi, M., Zeroual, A. et al., 2020. "Spatio-temporal analysis and forecasting of drought in the plains of northwestern Algeria using the standardized precipitation index". J Earth Syst Sci $129,42$. https://doi.org/10.1007/s12040-019-1306-3

Ali, Z., Hussain, I., Faisal, M., Shoukry, A. M., Gani, S., \& Ahmad, I. 2019. “A framework to identify homogeneous drought characterization regions". Theor Appl Climatol, 137(3-4), 3161-3172. https://doi.org/10.1007/s00704-019-02797-w

Anctil F, Pelletier G. 2011. "Analyse en ondelettes de fluctuations de débit en réseau de distribution d'eau potable”. Revue des sciences de l'eau 24(1):25-33. https://doi.org/10.7202/045825ar

Bouabdelli, S., Meddi, M., Zeroual, A., \& Alkama, R. 2020. "Hydrological drought risk recurrence under climate change in the karst area of Northwestern Algeria". Journal Water Clim Change. jwc2020207. https://doi.org/10.2166/wcc.2020.207

Boucherf, D. 2004. "Les changements climatiques en Algérie”. ONM, Alger.

Brito, T. T., Oliveira-Júnior, J. F., Lyra, G. B., Gois, G., \& Zeri, M. 2017. "Multivariate analysis applied to monthly rainfall over Rio de Janeiro state, Brazil”. Meteorol. Atmospheric Phys, 129(5), 469-478. https://doi.org/10.1007/s00703-016-0481-X

Caloiero, T., Aristodemo, F., \& Ferraro, D. A. 2019. "Trend analysis of significant wave height and energy period in southern Italy". Theor Appl Climatol, 1-14. https://doi.org/10.1007/s00704-019-02879-9

Cislaghi, A., Masseroni, D., Massari, C., Camici, S., \& Brocca, L. (2020). Combining a rainfall-runoff model and a regionalization approach for flood and water resource assessment in the western Po Valley, Italy. Hydrolog Sci J., 65(3), 348-370. https://doi.org/10.1080/02626667.2019.1690656 
Conway, D., Persechino, A., Ardoin-Bardin, S., Hamandawana, H., Dieulin, C., \& Mahé, G. (2009). Rainfall and water resources variability in sub-Saharan Africa during the twentieth century. J Hydrometeorol, 10(1), 41-59. https://doi.org/10.1175/2008JHM1004.1

Da Silva RM, Celso A, Santos G, Moreira M, Corte-real J, Valeriano C, Medeiros IC . 2015. "Rainfall and river flow trends using Mann-Kendall and Sen's slope estimator statistical tests in the Cobres River basin". Nat Hazards 77(2):1205-1221. https://doi.org/10.1007/s11069-015-1644-7

Dang, C., Zhang, H., Singh, V. P., Yu, Y., \& Shao, S. (2021). Investigating Hydrological Variability in the Wuding River Basin: Implications for Water Resources Management Under the Water-Human-Coupled Environment. Water, 13(2), 184. https://doi.org/10.3390/w13020184

Duncan, J. M., Biggs, E. M., Dash, J., \& Atkinson, P. M. (2013). Spatio-temporal trends in precipitation and their implications for water resources management in climate-sensitive Nepal. Appl Geogr., 43, 138-146. https://doi.org/10.1016/j.apgeog.2013.06.011

Everitt, B. S., \& Dunn, G. 1991. “Applied multivariate data analysis”. (No. 519.5076 E9).

Fathian, F., \& Dehghan, Z. 2019. "Using hybrid weighting-clustering approach for regional frequency analysis of maximum 24-hr rainfall based on climatic, geographical, and statistical attributes". Int J Climatol , 39(11), 4413-4428. https://doi.org/10.1002/joc.6082

Fazel, N., Berndtsson, R., Uvo, C. B., Madani, K., \& Kløve, B. 2018. "Regionalization of precipitation characteristics in Iran's Lake Urmia basin". Theor Appl Climatol, 132(1-2), 363-373. https://doi.org/10.1007/s00704-0172090-0

García-Marín, A. P., Estévez, J., Medina-Cobo, M. T., \& Ayuso-Muñoz, J. L. 2015. "Delimiting homogeneous regions using the multifractal properties of validated rainfall data series". J Hydrol, 529, 106-119. https://doi.org/10.1016/j.jhydrol.2015.07.021

Gocic, M., \& Trajkovic, S. 2014. "Spatiotemporal characteristics of drought in Serbia". J Hydrol, 510, 110-123. https://doi.org/10.1016/j.jhydrol.2013.12.030

Grinsted A, Moore JC, Jevrejeva S. 2004. "Application of the cross wavelet transform and wavelet coherence to geophysical time series”. Nonlinear Process Geophys 11:561-566. https://doi.org/10.5194/npg-11-561-2004

Hallouz, F., Meddi, M., Mahé, G. et al., 2020. “Analysis of meteorological drought sequences at various timescales in semi-arid climate: case of the Cheliff watershed (northwest of Algeria)". Arab J Geosci 13, 280. https://doi.org/10.1007/s12517-020-5256-5

Hamlaoui-Moulai, L., Mesbah, M., Souag-Gamane, D. et al., 2013. "Detecting hydro-climatic change using spatiotemporal analysis of rainfall time series in Western Algeria". Nat Hazards 65, 1293-1311. https://doi.org/10.1007/s11069-012-0411-2

Hasanean H M . "2004 Variability of the North Atlantic subtropical high and associations with tropical sea-surface temperature". Int J Climatol 24(8) 945-957. https://doi.org/10.1002/joc.1042

Hoffmann, L., El Idrissi, A., Pfister, L., Hingray, B., Guex, F., Musy, A., ... \& Leviandier, T. 2004. "Development of regionalized hydrological models in an area with short hydrological observation series". River Res Appl 20(3), 243-254. https://doi.org/10.1002/rra.774

Intergovernmental Panel on Climate Change (IPCC). 2014. "The fifth assessment report (AR5) “. $<$ http:/www.ipcc.ch/> (Feb. 15, 2020)

Jemai, H., Ellouze, M., Abida, H., \& Laignel, B. 2018. "Spatial and temporal variability of rainfall: case of BizerteIchkeul Basin (Northern Tunisia) “. Arab J Geosci, 11(8), 177. https://doi.org/10.1007/s12517-018-3482-x 
Joan Martinez-Artigas, Marc Lemus-Canovas and Joan Albert Lopez-Bustins. 2020. "Precipitation in peninsular Spain: Influence of teleconnection indices and spatial regionalization. Int $\mathrm{J}$ Climatol https://doi.org/10.1002/joc.6770

Khedimallah, A., Meddi, M. \& Mahé, G. (2020). "Characterization of the interannual variability of precipitation and runoff in the Cheliff and Medjerda basins (Algeria)". J Earth Syst Sci 129, 134. https://doi.org/10.1007/s12040-020-01385-1

Khezazna, A., Amarchi, H., Derdous, O., \& Bousakhria, F. 2017. "Drought monitoring in the Seybouse basin (Algeria) over the last decades". J. Water Land Dev, 33(1), 79-88. https://doi.org/10.1515/jwld-2017-0022

Labat, D. 2005. "Recent advances in wavelet analyses: Part 1. A review of concepts". J Hydrol, 314(1-4), 275-288. https://doi.org/10.1016/j.jhydrol.2005.04.003

Lazri, M., \& Ameur, S. 2018. "Combination of support vector machine, artificial neural network and random forest for improving the classification of convective and stratiform rain using spectral features of SEVIRI data". Atmos Res, 203, 118-129. https://doi.org/10.1016/j.atmosres.2017.12.006

Li, Q., He, P., He, Y., Han, X., Zeng, T., Lu, G., \& Wang, H. (2020). Investigation to the relation between meteorological drought and hydrological drought in the upper Shaying River Basin using wavelet analysis. Atmos Res, 234, 104743. https://doi.org/10.1016/j.atmosres.2016.07.030

López-Moreno, J. I., Vicente-Serrano, S. M., Morán-Tejeda, E., et al. 2011. "Effects of the North Atlantic Oscillation (NAO) on combined temperature and precipitation winter modes in the Mediterranean mountains : observed relationships and projections for the 21st century". Glob. Planet. Change, 77(1), 62-76. https://doi.org/10.1016/j.gloplacha.2011.03.003

Lyra, G. B., Oliveira-Júnior, J. F., \& Zeri, M. 2014. "Cluster analysis applied to the spatial and temporal variability of monthly rainfall in Alagoas state, Northeast of Brazil". Int J Climatol , 34(13), 3546-3558. https://doi.org/10.1002/joc.3926

Machiwal, D., Kumar, S., Meena, H. M., Santra, P., Singh, R. K., \& Singh, D. V. 2019. "Clustering of rainfall stations and distinguishing influential factors using PCA and HCA techniques over the western dry region of India". Meteorol. Appl. 26(2), 300-311. https://doi.org/10.1002/met.1763

Massei, N, B Laignel, and N Fritier 2011. "Rapport Seine-Aval 4".

Massei, N., Dieppois, B., Hannah, D. M., Lavers, D. A., Fossa, M., Laignel, B., and Debret, M. (2017). Multi-timescale hydroclimate dynamics of a regional watershed and links to large-scale atmospheric circulation: Application to the Seine river catchment, France. J Hydrol, 546:262-275. https://doi.org/10.1016/j.jhydrol.2017.01.008

Mathbout S, Lopez- Bustins JA, Royé D, Martin-Vide J, Benhamrouche A. 2019. "Spatiotemporal variability of daily precipitation concentration and its relationship to teleconnection patterns over the Mediterranean during 19752015”. Int J Climatol; 1-21. https://doi.org/10.1002/joc.6278

McCabe, M. F., Rodell, M., Alsdorf, D. E., Miralles, D. G., Uijlenhoet, R., Wagner, W., ... \& Shi, J. 2017. "The future of Earth observation in hydrology". Hydrol. Earth Syst. Sci 21(7), 3879. https://doi.org/ 10.5194/hess-21$3879-2017$

Meddi, M. M., Assani, A. A., \& Meddi, H. 2010. "Temporal variability of annual rainfall in the Macta and Tafna catchments, Northwestern Algeria". Water Resour Manage , 24(14), 3817-3833. https://doi.org/10.1007/s11269-010-9635-7

Meddour Rachid 2010. "Bioclimatologie, phytogéographie et phytosociologie en Algérie. Exemple des groupements forestiers et préforestiers de la Kabylie Djurdjurenne". Doctoral dissertation, Université Mouloud Maameri de Tizi Ouzou. 461 p 
Mellak, S., \& Souag-Gamane, D. 2020. "Spatio-temporal analysis of maximum drought severity using Copulas in Northern Algeria". Journal Water Clim Change. jwc2020070. https://doi.org/10.2166/wcc.2020.070

Mengistu, D., Bewket, W., Dosio, A., \& Panitz, H. J. (2021). Climate change impacts on water resources in the Upper Blue Nile (Abay) River Basin, Ethiopia. J Hydrol, 592, 125614. https://doi.org/10.1016/j.heliyon.2018.e00771

Merabti, A., Martins, D. S., Meddi, M. \& Pereira, L. S. 2018. "Spatial and time variability of drought based on SPI and RDI with various time scales". Water Resour Manage 32, 1087. https://doi.org/10.1007/s11269-017$1856-6$.

Merabti, A., Meddi, M., Martins, D.S. et al. Comparing SPI and RDI Applied at Local Scale as Influenced by Climate. Water Resour Manage 32, 1071-1085 (2018). https://doi.org/10.1007/s11269-017-1855-7

Mokdad, F., \& Haddad, B. 2017. "Improved infrared precipitation estimation approaches based on k-means clustering: Application to north Algeria using MSG-SEVIRI satellite data. Adv. Space Res., 59(12), 2880-2900. https://doi.org/10.1016/j.asr.2017.03.027

Mrad, D., Dairi, S., Boukhari, S., \& Djebbar, Y. 2019. "Applied multivariate analysis on annual rainfall in the northeast of Algeria”. Journal Water Clim Change. https://doi.org/10.2166/wcc.2019.272

Mühlbauer S, Costa AC, Caetano M. 2016. "A spatiotemporal analysis of droughts and the influence of North Atlantic oscillation in the Iberian Peninsula based on MODIS imagery". Theor Appl Climatol 124(3-4):703-721. https://doi.org/10.1007/s00704-015-1451-9

Munoz-Diaz D. and Rodrigo F. S. 2003. "Effects of the North Atlantic Oscillation on the probability for climatic categories of local monthly rainfall in Southern Spain. Int J Climatol 23: 381-397. . https://doi.org/10.1002/joc.886

Nakken, Margriet 1999. "Wavelet analysis of rainfall-runoff variability isolating climatic from anthropogenic patterns". Environ. Model. Softw.14: 283-295. http://dx.doi.org/10.1016/S1364-8152(98)00080-2

Nistor, M. M., Rai, P. K., Dugesar, V., Mishra, V. N., Singh, P., Arora, A., ... \& Carebia, I. A. (2020). Climate change effect on water resources in Varanasi district, India. Meteorol. Appl, 27(1), e1863. https://doi.org/10.1002/met.1863

Nouaceur Zeineddine and Murărescu Ovidiu. 2016. "Rainfall Variability and Trend Analysis of Annual Rainfall in North Africa". Int. J. Atmos. Sci., vol. 2016, Article ID 7230450, 12 pages. http://dx.doi.org/10.1155/2016/7230450

Ouachani R, Bargaoui Z, Ouarda T. 2013. "Power of teleconnection patterns on precipitation and streamflow variability of upper Medjerda Basin". Int J Climatol 33(1):58-76. https://doi.org/10.1002/joc.3407

Pathak, P., Kalra, A., \& Ahmad, S. (2017). Temperature and precipitation changes in the Midwestern United States: implications for water management. Int. J Water Resour. Dev, 33(6), 1003-1019. https://doi.org/10.1080/07900627.2016.1238343

Peña-Angulo, D., Nadal-Romero, E., González-Hidalgo, J. C., Albaladejo, J., Andreu, V., Bagarello, V., ... \& Campo, J. 2019. "Spatial variability of the relationships of runoff and sediment yield with weather types throughout the Mediterranean basin”. J Hydrol, 571, 390-405.https://doi.org/10.1016/j.jhydrol.2019.01.059

Peña-Angulo, D., Vicente-Serrano, S. M., Domínguez-Castro, F., Murphy, C., Reig, F., Tramblay, Y., ... \& AznárezBalta, M. (2020). Long-term precipitation in Southwestern Europe reveals no clear trend attributable to anthropogenic forcing. Environ Res Lett. https://doi.org/10.1088/1748-9326/ab9c4f

Philandras, C. M., Nastos, P. T., Kapsomenakis, J., Douvis, K. C., Tselioudis, G., \& Zerefos, C. S. 2011. "Long-term precipitation trends and variability within the Mediterranean region". Nat. Hazards Earth Syst. Sci., 11(12),3235-3250. https://doi.org/10.5194/nhess-11-3235-2011 
Piccarreta, M, A Pasini, D Capolongo, and M Lazzari. 2013. "Changes in Daily Precipitation Extremes in the Mediterranean from 1951 to 2010: The Basilicata Region, Southern Italy”. Int J Climatol 33, no. 15: 32293248. https://doi.org/10.1002/joc.3670

Pokharel, B., Wang, S. Y. S., Meyer, J., Marahatta, S., Nepal, B., Chikamoto, Y., \& Gillies, R. 2020. “The east-west division of changing precipitation in Nepal". Int $J$ Climatol, 40(7), 3348-3359. https://doi.org/10.1002/joc.6401

Rashid, M. M., Beecham, S., \& Chowdhury, R. K. 2015. "Assessment of trends in point rainfall using continuous wavelet transforms". Adv Water Resour, 82, 1-15. https://doi.org/10.1016/j.advwatres.2015.04.006.

Rata, M., Douaoui, A., Larid, M. et al., 2020. "Comparison of geostatistical interpolation methods to map annual rainfall in the Chéliff watershed, Algeria". Theor Appl Climatol 141, 1009-1024. https://doi.org/10.1007/s00704-020-03218-z

Rau, P., Bourrel, L., Labat, D., Melo, P., Dewitte, B., Frappart, F., ... \& Felipe, O. 2017. '’Regionalization of rainfall over the Peruvian Pacific slope and coast'. Int J Climatol, 37(1), 143-158. https://doi.org/10.1002/joc.4693

Rodriguez, R. D., Singh, V. P., Pruski, F. F., \& Calegario, A. T. 2016. "Using entropy theory to improve the definition of homogeneous regions in the semi-arid region of Brazil". Hydrolog Sci J., 61(11), 2096-2109. https://doi.org/10.1080/02626667.2015.1083651

Roushangar, K., \& Alizadeh, F. 2019. "Using multi-temporal analysis to classify monthly precipitation based on maximal overlap discrete wavelet transform". J Hydroinform, 21(4), 541-557. https://doi.org/10.2166/hydro.2019.021

Samantaray, A. K., Mitra, A., Ramadas, M., \& Panda, R. K. (2021). Regionalization of hydroclimatic variables using Markov random field model for climate change impact assessment. J Hydrol, 596, 126071. https://doi.org/10.1016/j.jhydrol.2021.126071

Santos, C. A. G., \& de Morais, B. S. (2013). Identification of precipitation zones within São Francisco River basin (Brazil) by global wavelet power spectra. Hydrolog Sci J., 58(4), 789-796. https://doi.org/10.1080/02626667.2013.778412

Santos, C. A. G., Kisi, O., da Silva, R. M., \& Zounemat-Kermani, M. 2018. "Wavelet-based variability on streamflow at 40-year timescale in the Black Sea region of Turkey". Arab J Geosci, 11(8), 169. https://doi.org/10.1007/s12517-018-3514-6

Santos, C. A. G.; Brasil Neto, R.M.; Silva, R.M.; Costa, S.G.F. Cluster analysis applied to spatiotemporal variability of monthly precipitation over Paraíba state using Tropical Rainfall Measuring Mission (TRMM) data. Remote Sens, 11, 637, 2019. http://dx.doi.org/10.3390/rs11060637

Santos, C. A. G.; Galvão, C. O.; Suzuki, K.; Trigo, R. M. matsuyama city rainfall data analysis using wavelet transform. Proceedings of Hydraulic Engineering, Tokyo, 45, 211-216, 2001. http://dx.doi.org/10.2208/prohe.45.211

Sun Q, Kong D, Miao C, Duan Q, Yang T, Ye A, Gong W. 2014. "Variations in global temperature and precipitation for the period of 1948 to 2010". Environ Monit Assess. 186(9):5663-5679. https://doi.org/10.1007/s10661014-3811-9

Taibi, S., Meddi, M., \& Mahé, G. 2019. "Seasonal rainfall variability in the southern Mediterranean border: Observations, regional model simulations and future climate projections". Atmósfera, 32(1), 39-54. https://doi:10.20937/atm.2019.32.01.04

Taibi, S., Meddi, M., Mahé, G., \& Assani, A. 2017. "Relationships between atmospheric circulation indices and rainfall in Northern Algeria and comparison of observed and RCM-generated rainfall". Theor Appl Climatol, 127(12), 241-257. https://doi.org/10.1007/s00704-015-1626-4 
Teodoro, P. E., de Oliveira-Júnior, J. F., Da Cunha, E. R., Correa, C. C. G., Torres, F. E., Bacani, V. M., ... \& Ribeiro, L. P. 2016. "Cluster analysis applied to the spatial and temporal variability of monthly rainfall in Mato Grosso do Sul State, Brazil”. Meteorol. Atmospheric Phys, 128(2), 197-209. https://doi.org/10.1007/s00703-0150408-y

Torrence C, Compo GP. 1998. “A practical guide to wavelet analysis”. B Am Meteorol Soc 79:61-78. https://doi.org/10.1175/1520

Truche, C. 2010. “Caractérisation et quantification des minéraux argileux dans les sols expansifs par spectroscopie infrarouge aux échelles du laboratoire et du terrain “. Doctoral dissertation, Université Paul Sabatier-Toulouse III.

Ullah, H., Akbar, M., \& Khan, F. 2020. "Construction of homogeneous climatic regions by combining cluster analysis and L-moment approach on the basis of Reconnaissance Drought Index for Pakistan”. Int J Climatol, 40(1), 324-341. https://doi.org/10.1002/joc.6214

Vergni L, Di Lena B, Chiaudani A. 2016. "Statistical characterisation of winter precipitation in the Abruzzo region (Italy) in relation to the North Atlantic oscillation (NAO) ".Atmos. Res 178:279-290. https://doi.org/10.1016/j.atmosres.2016.03.028

Wang, N., \& Yin, J. 2019. "Self-organizing map network-based precipitation regionalization for the Tibetan Plateau and regional precipitation variability". Theor Appl Climatol, 135(1-2), 29-44. https://doi.org/10.1007/s00704017-2349-5

Ward JH. 1963. "Hierarchical grouping to optimize an objective function”. J Am Stat Assoc 58(301):236-244. https://doi.org//10.1080/01621459.1963.10500845

Wilks, D. S. 1995. "Statistical Methods in the Atmospheric Sciences”. Academic Press, 467 pp.

Wolski, P., Conradie, S., Jack, C., \& Tadross, M. (2021). Spatio-temporal patterns of rainfall trends and the 20152017 drought over the winter rainfall region of South Africa. Int J Climatol, 41, E1303-E1319. https://doi.org/10.1002/joc.6768

Xoplaki, E., González-Rouco, J. F., Luterbacher, J., \& Wanner, H. 2004. "Wet season Mediterranean precipitation variability: influence of large-scale dynamics and trends". Clim Dyn, 23(1), 63-78. https://doi.org/10.1007/s00382-004-0422-0

Zamrane Z, Turki I, Laignel B, Mahe G and Laftouhi N E .2016. "Characterization of the interannual variability of precipitation and streamflow in Tensift and Ksob basins (Morocco) and links with the NAO”. Atmosphere 7(6) 84. https://doi.org/10.3390/atmos7060084

Zeroual A, Assani AA, Meddi M. 2017. "Combined analysis of temperature and rainfall variability as they relate to climate indices in northern Algeria over the 1972-2013 period". Hydrol Res 48(2):584-595. https://doi.org/10.2166/nh.2016.244

Zeroual, A., Assani, A.A., Meddi, M. et al. (2019). Assessment of climate change in Algeria from 1951 to 2098 using the Köppen-Geiger climate classification scheme. Clim Dyn 52, 227-243. https://doi.org/10.1007/s00382018-4128-0

Zerouali, B., Chettih, M., Abda, Z., Mesbah, M., \& Djemai, M. (2020). '’The use of hybrid methods for change points and trends detection in rainfall series of northern Algeria". Acta Geophys, 68(5), 1443-1460." . https://doi.org/10.1007/s11600-020-00466-5

Zerouali, B., Chettih, M., Abda, Z., Mesbah, M., Santos, C. A. G., Neto, R. M. B., \& da Silva, R. M. (2021). Spatiotemporal meteorological drought assessment in a humid Mediterranean region: case study of the Oued Sebaou basin (northern central Algeria). Nat Hazards, 1-21. https://doi.org/10.1007/s11069-021-04701-0 
Zerouali, B., Mesbah, M., Chettih, M., \& Djemai, M. 2018. "Contribution of cross time-frequency analysis in assessment of possible relationships between large-scale climatic fluctuations and rainfall of northern central Algeria”. Arab J Geosci, 11(14), 392. https://doi.org/10.1007/s12517-018-3728-7 


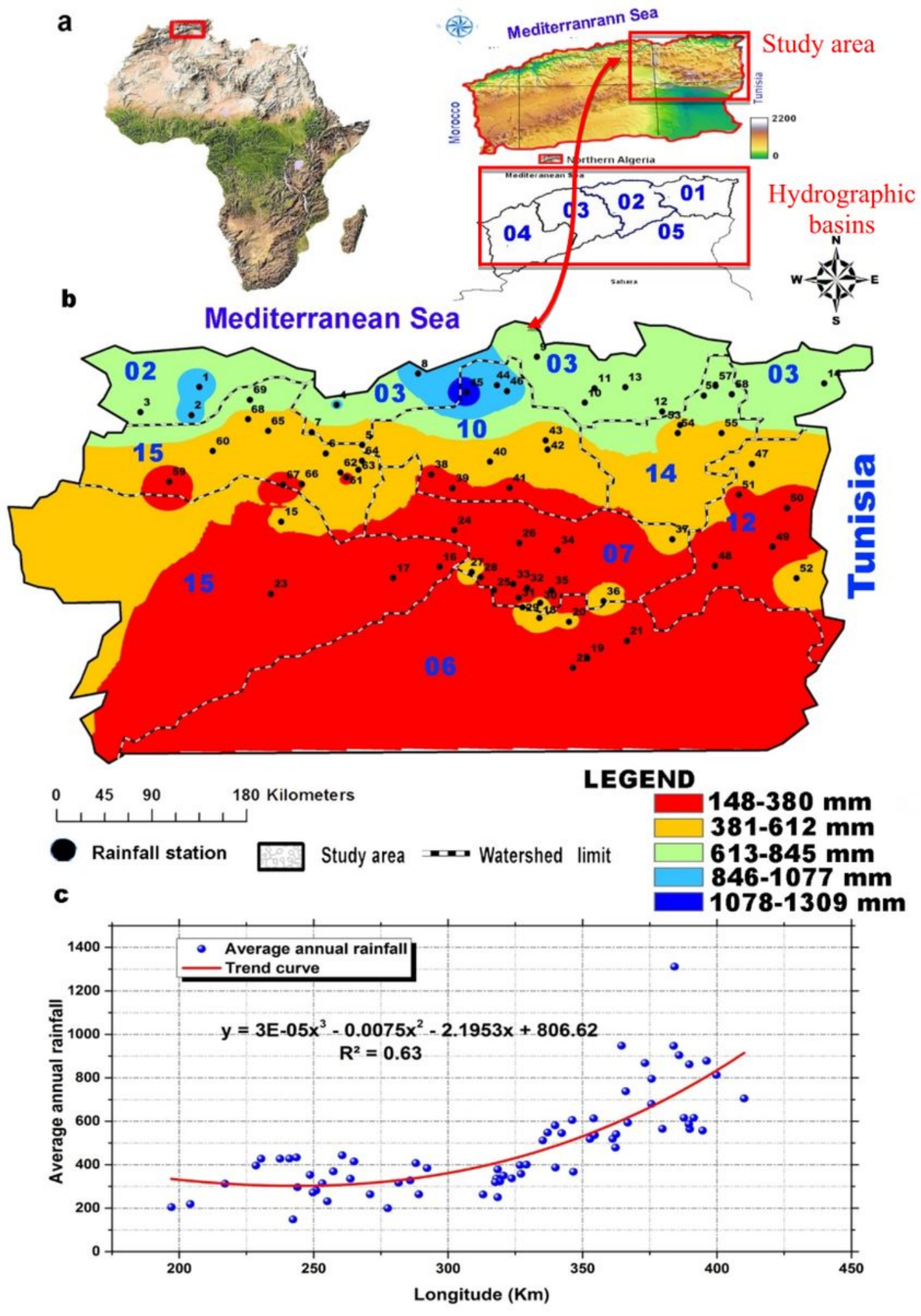

Figure 1

Representation of (a) northern Algeria, (b) the study area, the average annual rainfall at the rain gauges used in the analysis and (c) the relationship between the average annual rainfall and longitudes of the rain gauges. Note: The designations employed and the presentation of the material on this map do not 
imply the expression of any opinion whatsoever on the part of Research Square concerning the legal status of any country, territory, city or area or of its authorities, or concerning the delimitation of its frontiers or boundaries. This map has been provided by the authors.

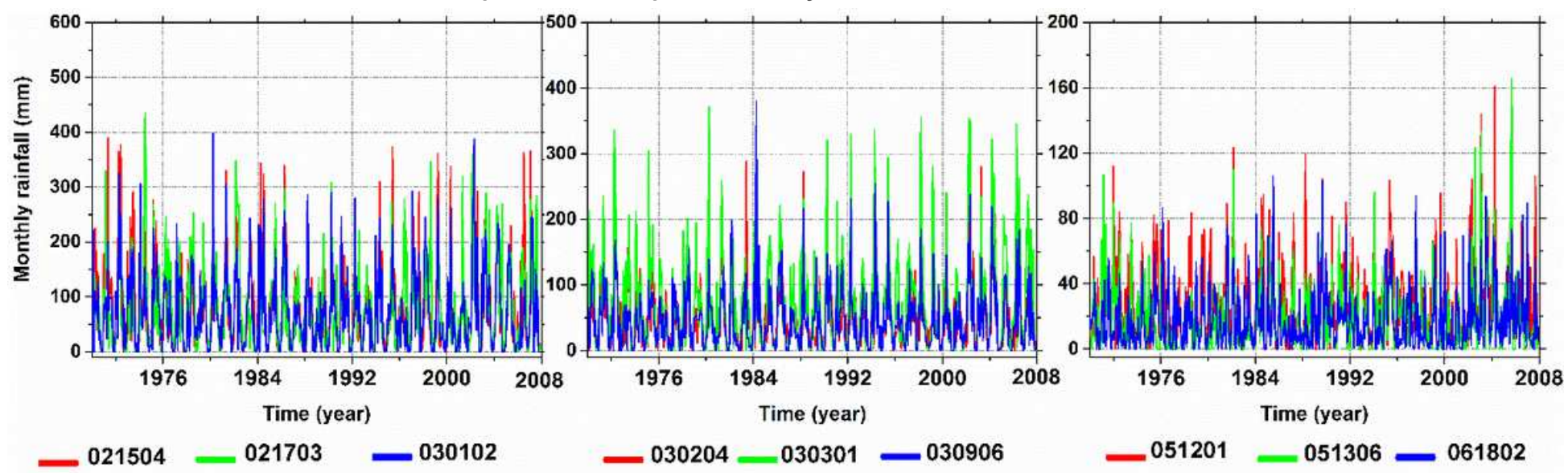

Figure 2

Representation of select rainfall time series that are representative of the study area. 
(a)

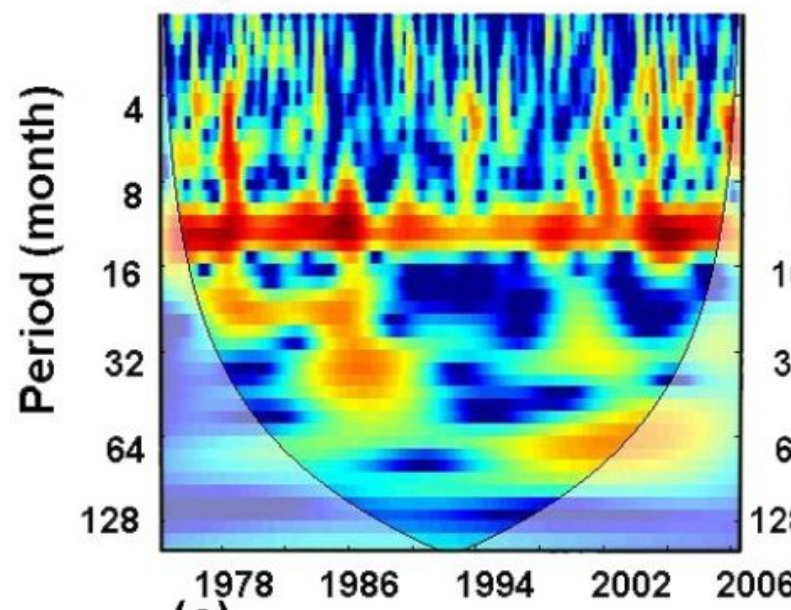

(c)

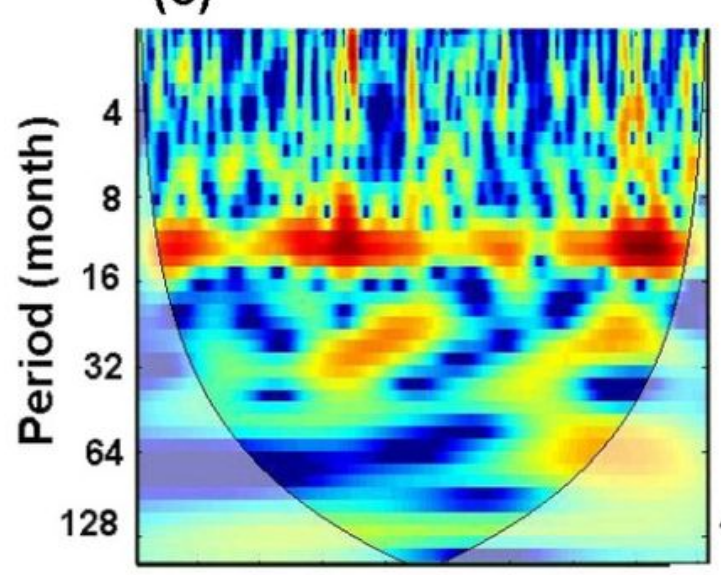

1970

(e)

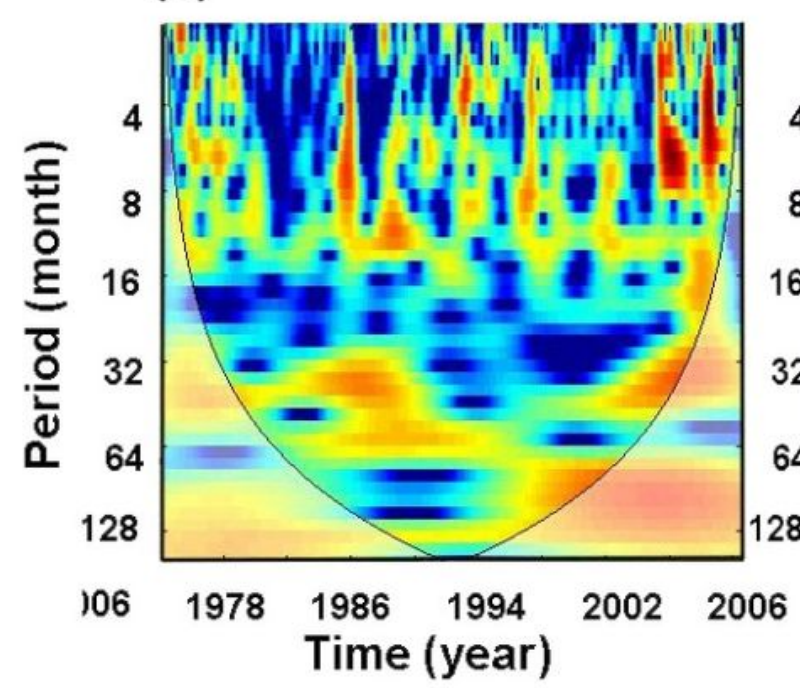

(b)

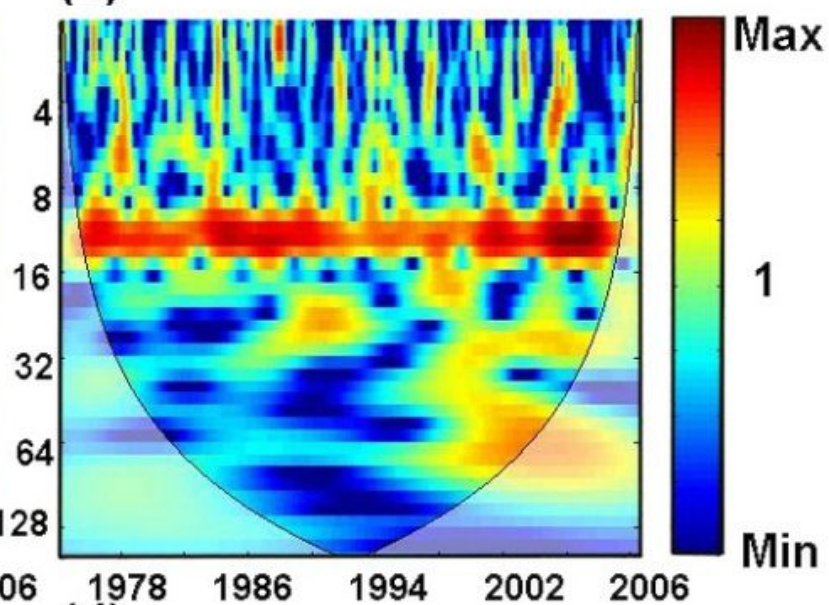

(d)

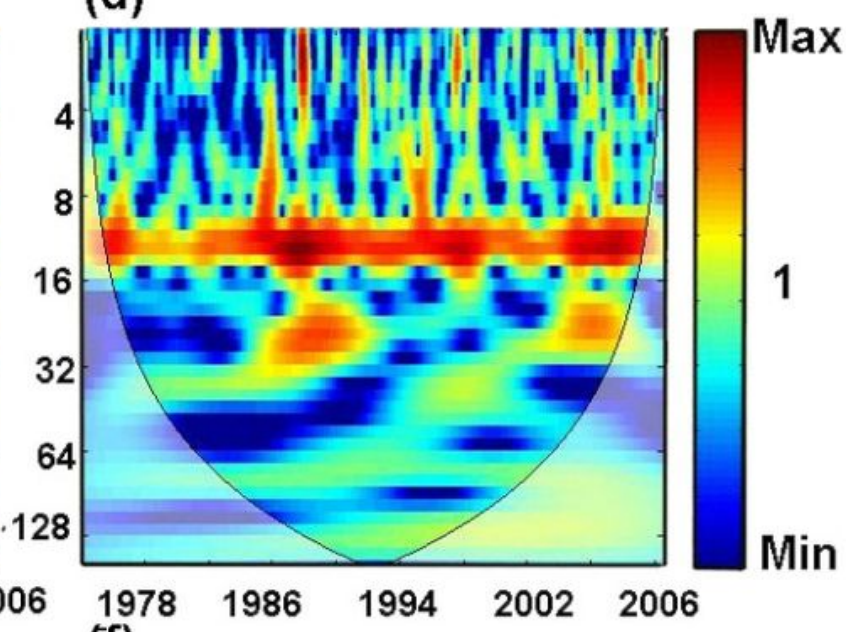

(f)

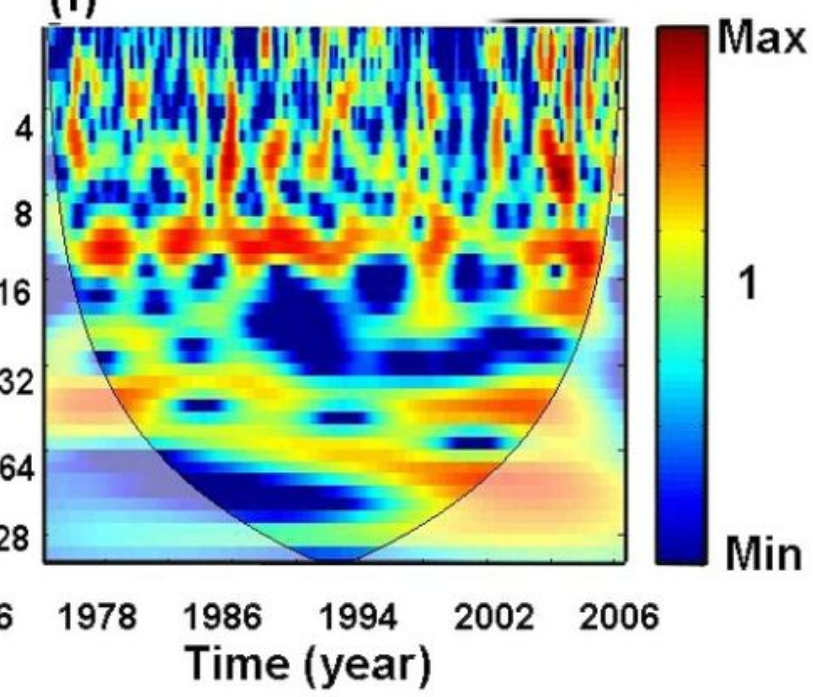

Figure 3

Morlet continuous wavelet spectra of the rain gauges (a) 021703, (b) 030102, (c) 030204, (d) 030906, (e) 051306 and (f) 051201. (Items outside the COl, which is outlined in black, are not statistically significant). 
(a)

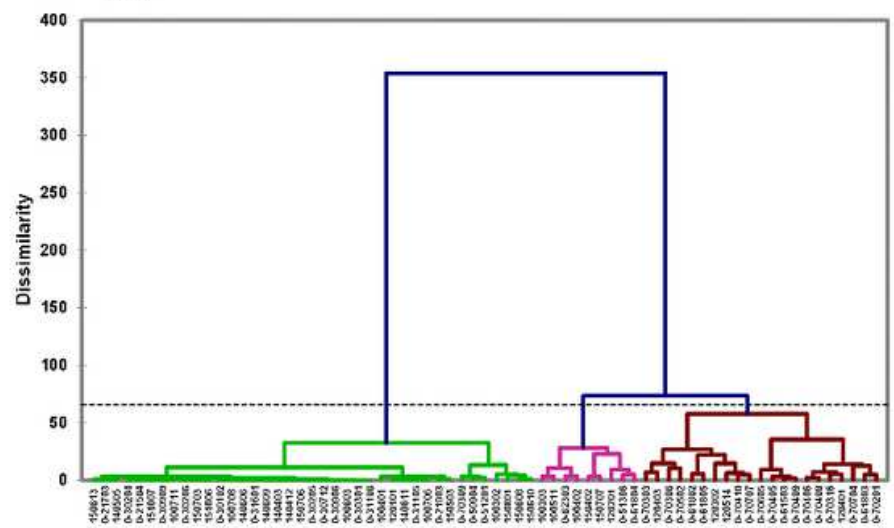

(c)

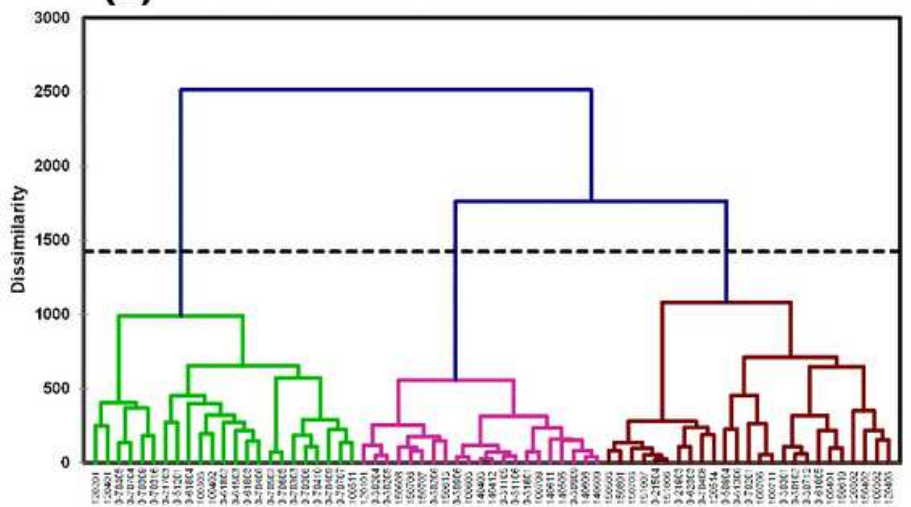

Rain gauge ID (b)

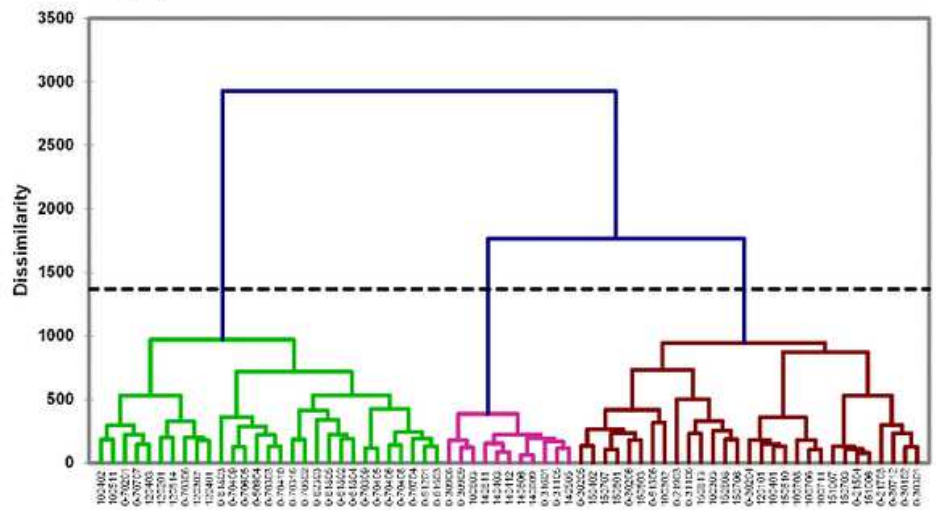

(d)

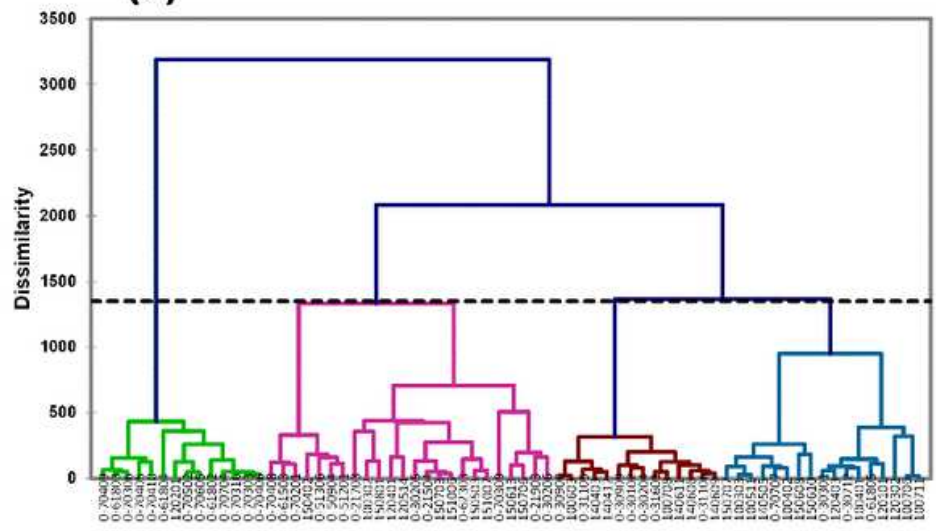

Rain gauge ID

Figure 4

Dendrograms of homogeneous regions obtained by the AHC of the (a) global wavelet spectrum, (b) 3-6month, (c) 8-16-month and (d) 1-3-year scale-average variances, based on monthly rainfall in northeastern Algeria. 


\section{Mediterranean Sea}
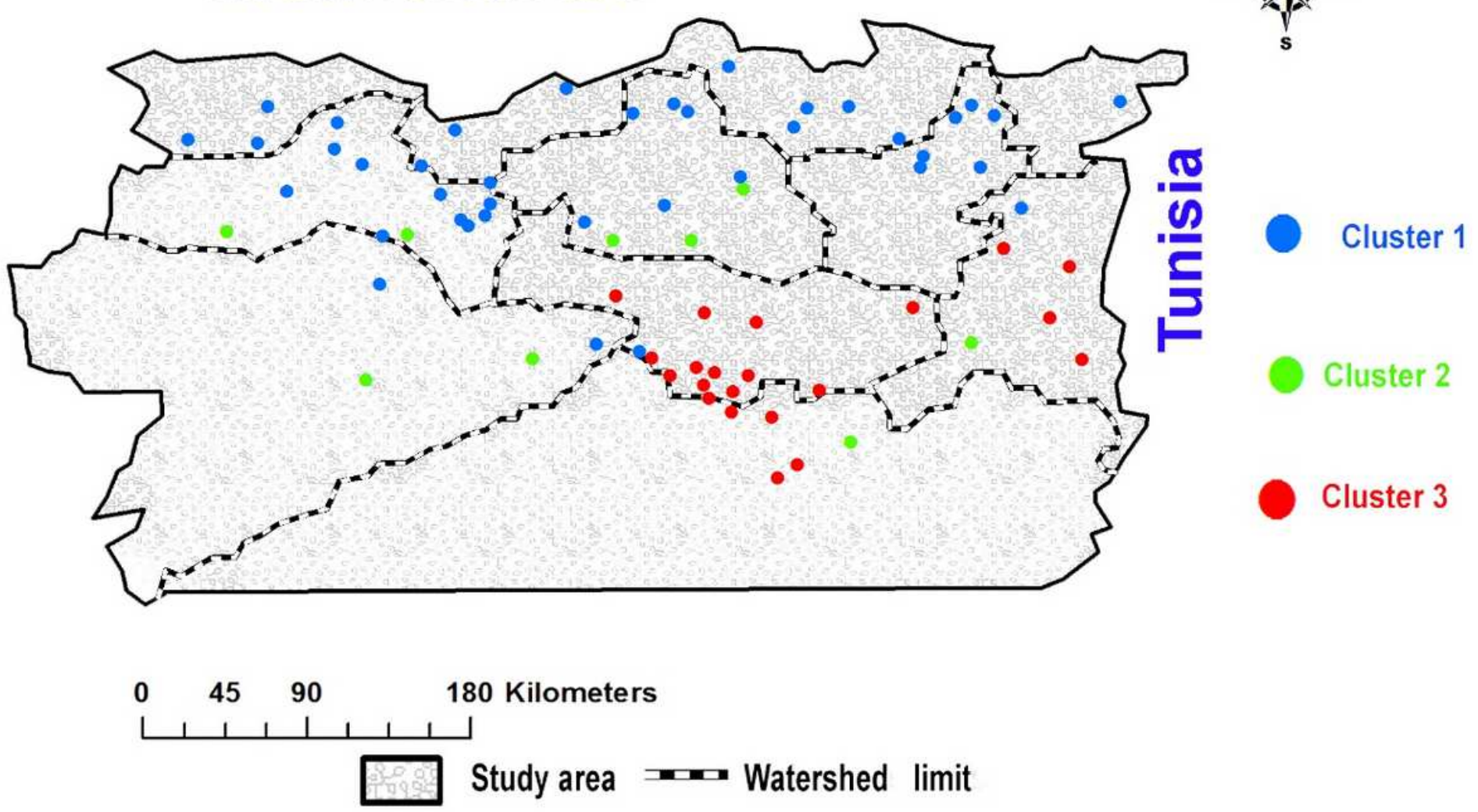

Figure 5

Spatial distribution of homogeneous groups obtained by applying the hierarchical ascending classification to the global wavelet spectra. Note: The designations employed and the presentation of the material on this map do not imply the expression of any opinion whatsoever on the part of Research Square concerning the legal status of any country, territory, city or area or of its authorities, or concerning the delimitation of its frontiers or boundaries. This map has been provided by the authors. 


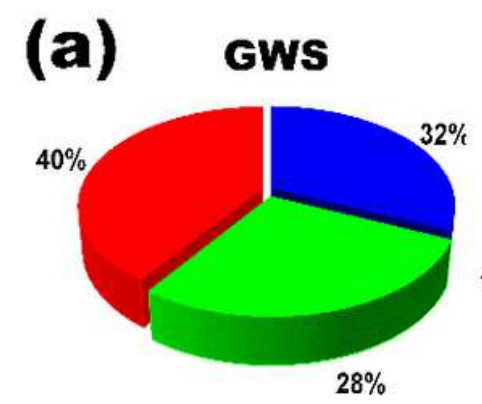

(b) Gws
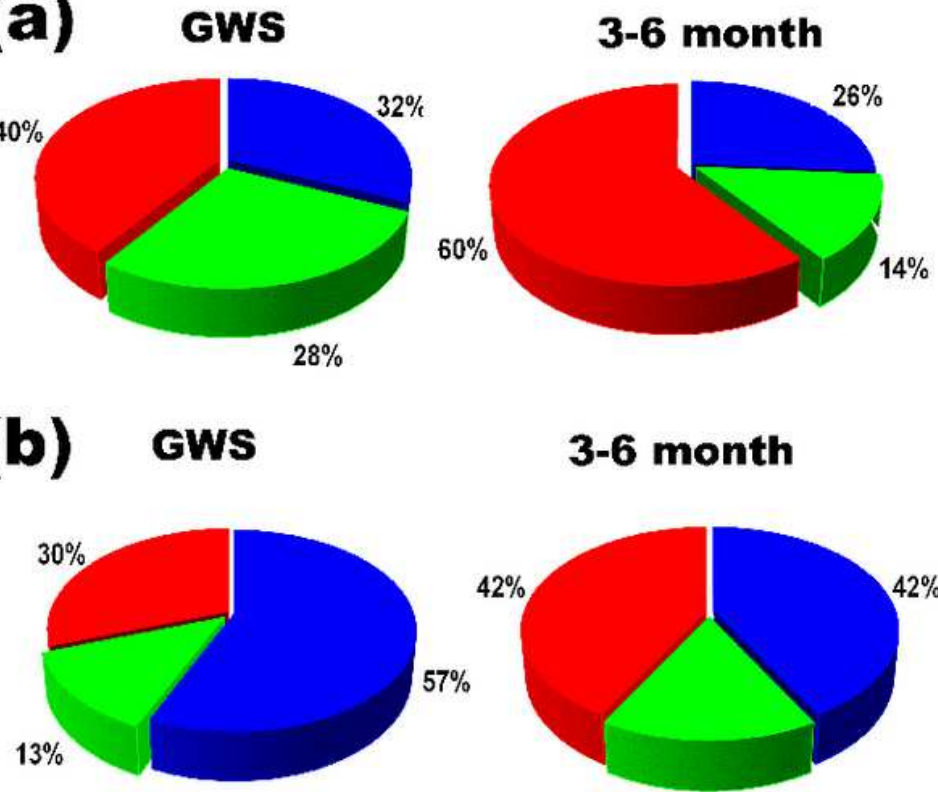

3-6 month

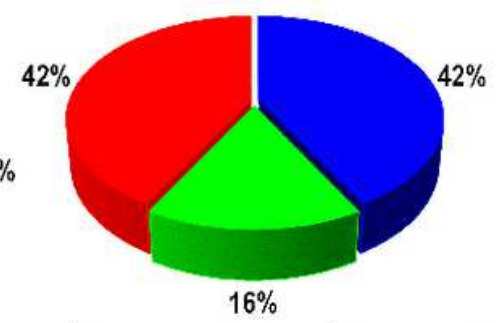

Cluster 1

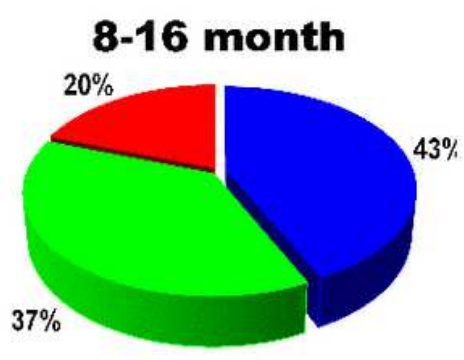

8-16 month

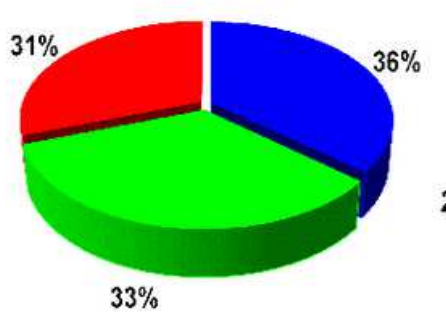

$33 \%$

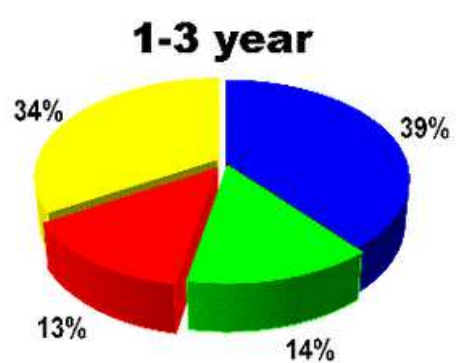

1-3 year

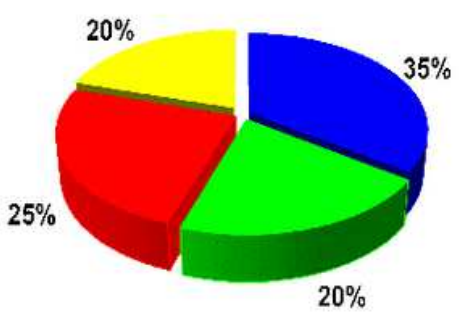

Cluster 2 Cluster 3 Cluster 4

Figure 6

Contribution, in percentage, of (a) the area of each group to the total study area and (b) the percentage of rain gauges included in each group compared to all rain gauges used in the analysis during the period 1970-2007. 

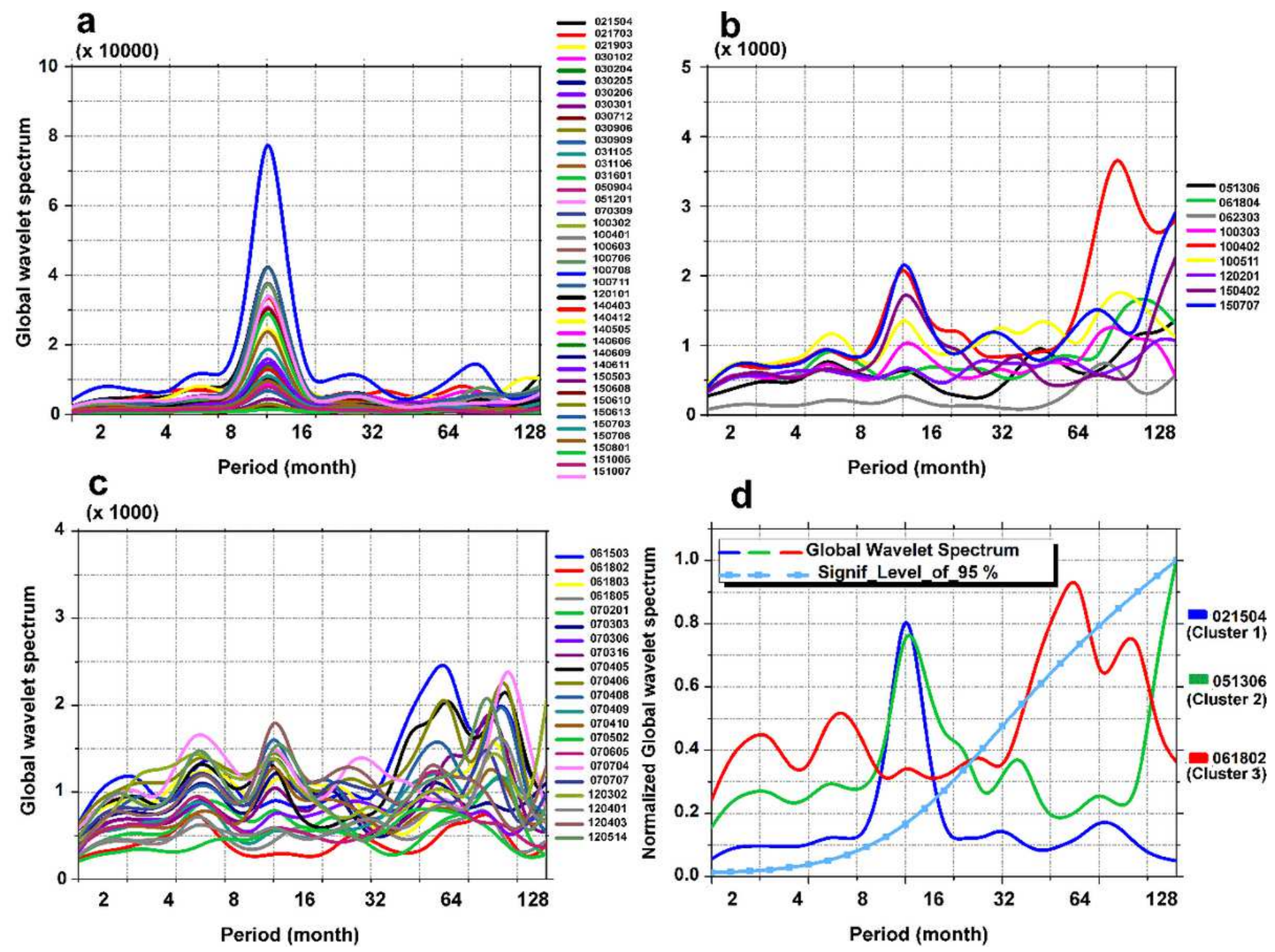

Figure 7

Global wavelet spectra of the rainfall of (a) Cluster 1, (b) Cluster 2, (c) Cluster 3, and (d) select global normalized spectra representative of each obtained group (the light blue line represents the $95 \%$ confidence level). 
(a)

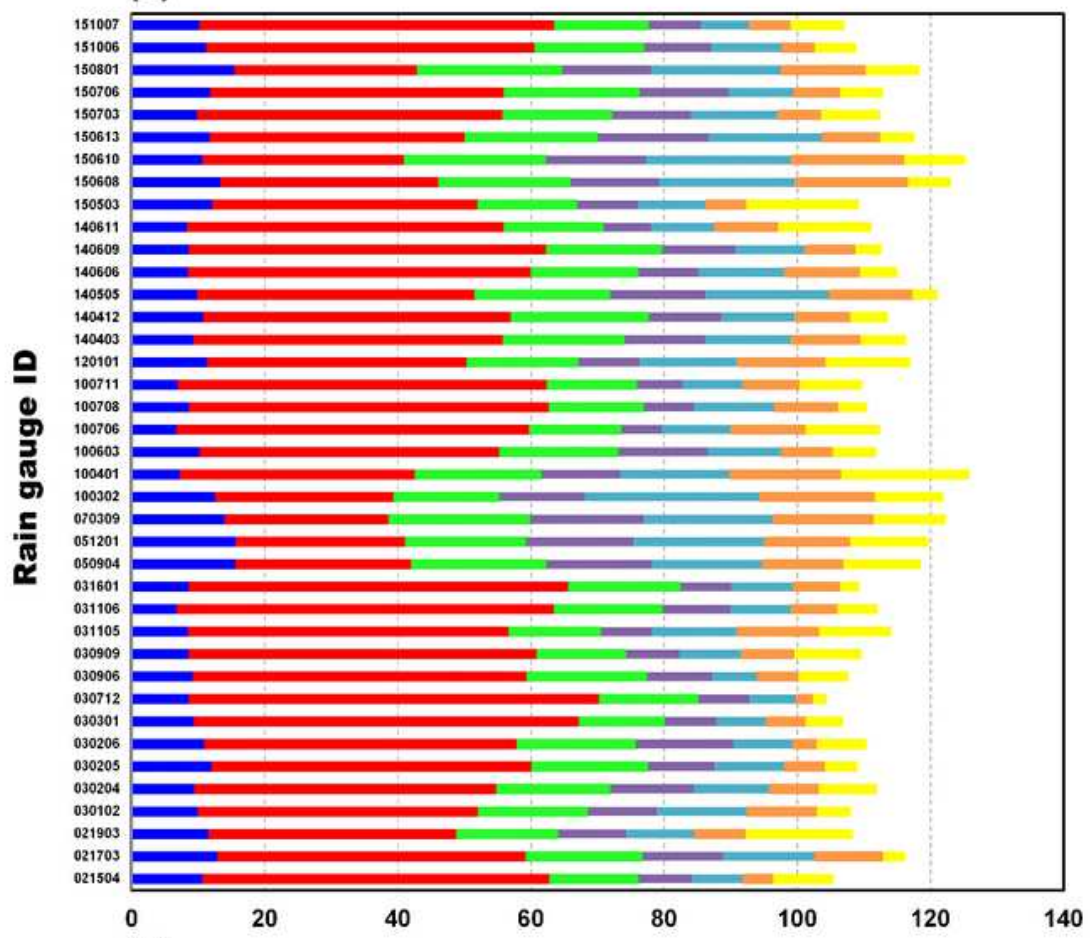

-3-6 Month

8-16 Month

(b)

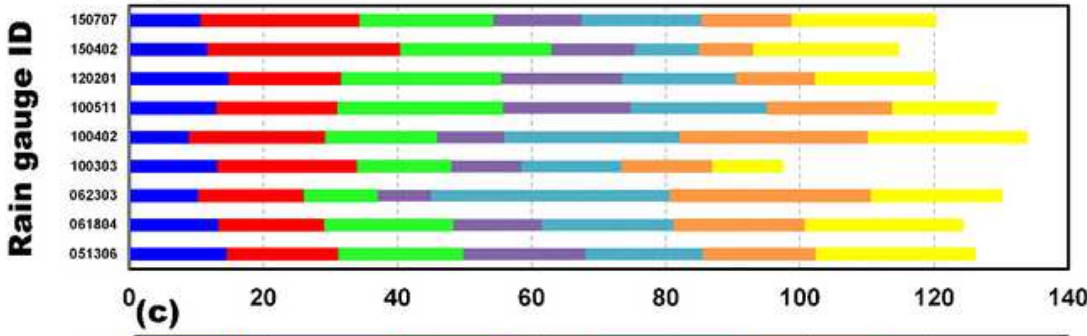

1-3 Years

-2-4 Years

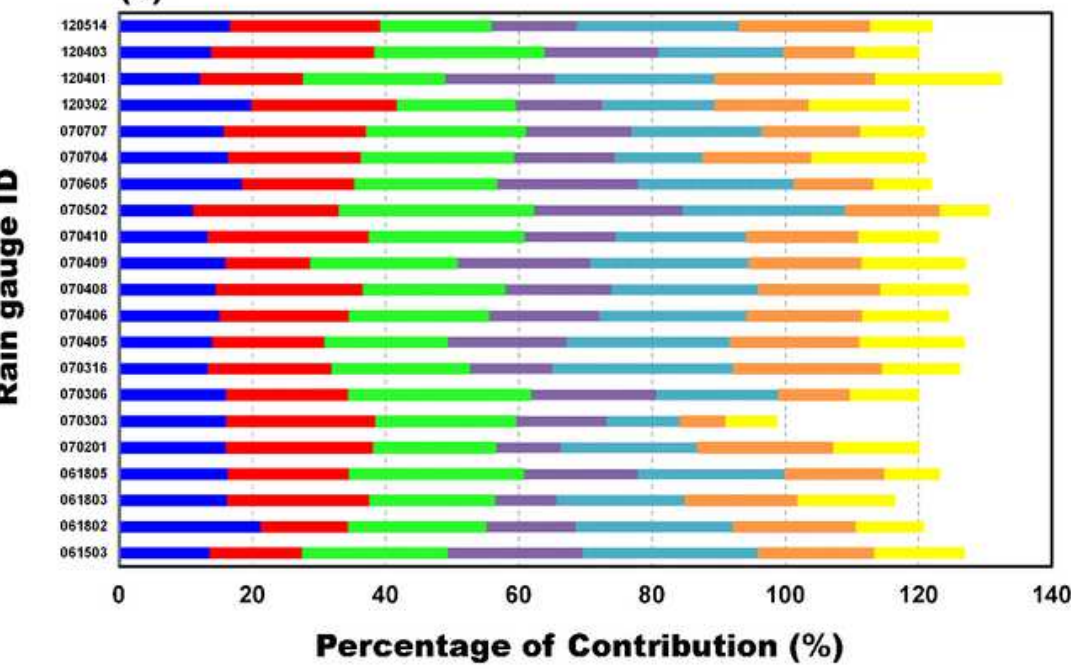

-3-6 Years

6-8 Years

8-12 Years

Figure 8

Percent contributions of the selected energy bands to the total variance for the rainfall of (a) Cluster 1, (b) Cluster 2 and (c) Cluster 3 of different modes of variability resulting from the GWS. 
(a)

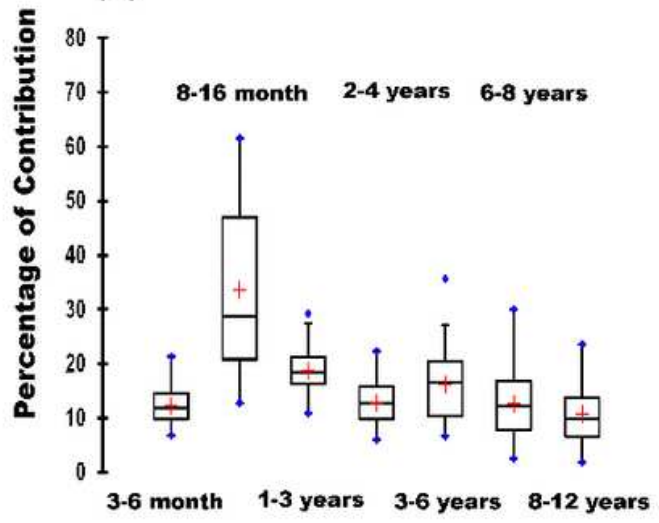

(b)

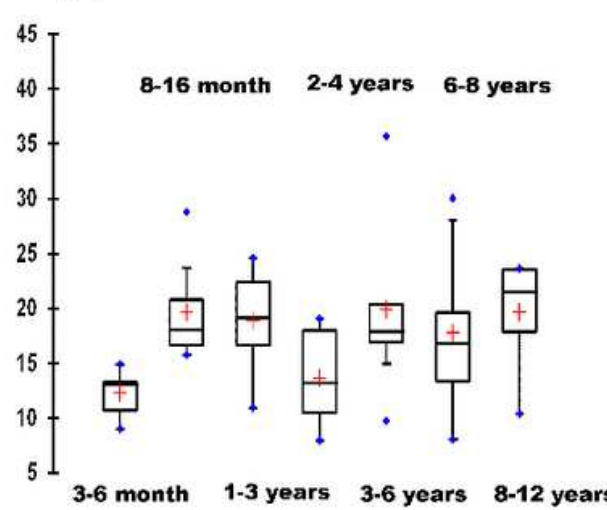

(c)

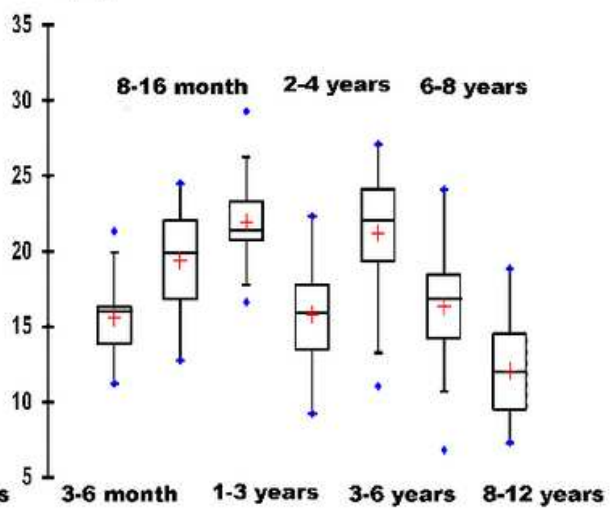

Figure 9

Box plot of the statistical characteristics of the percent contributions of the selected energy bands to the total variance for the rainfall of (a) Cluster 1, (b) Cluster 2 and (c) Cluster 3 of different modes of variability resulting from the GWS.

(a) Mediterranean Sea

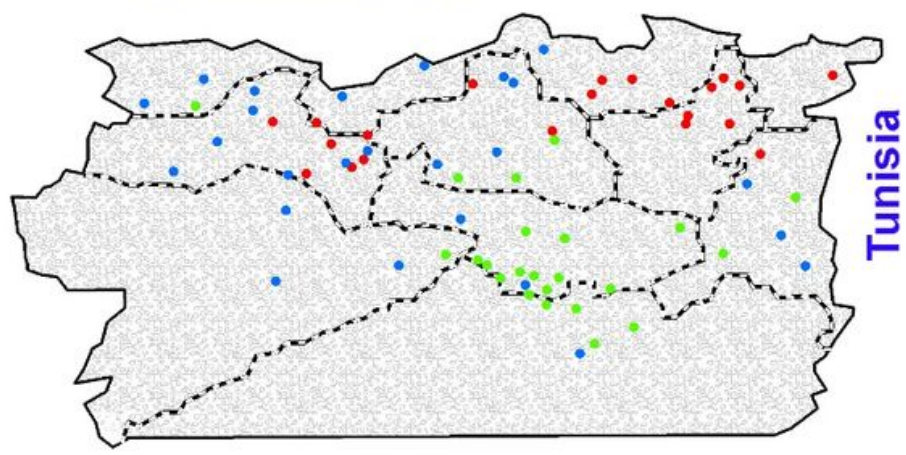

$\begin{array}{llll}0 & 45 \quad 90 & 180 \text { Kilometers }\end{array}$

Study area $=$ Watershed limit (b) Mediterranean Sea
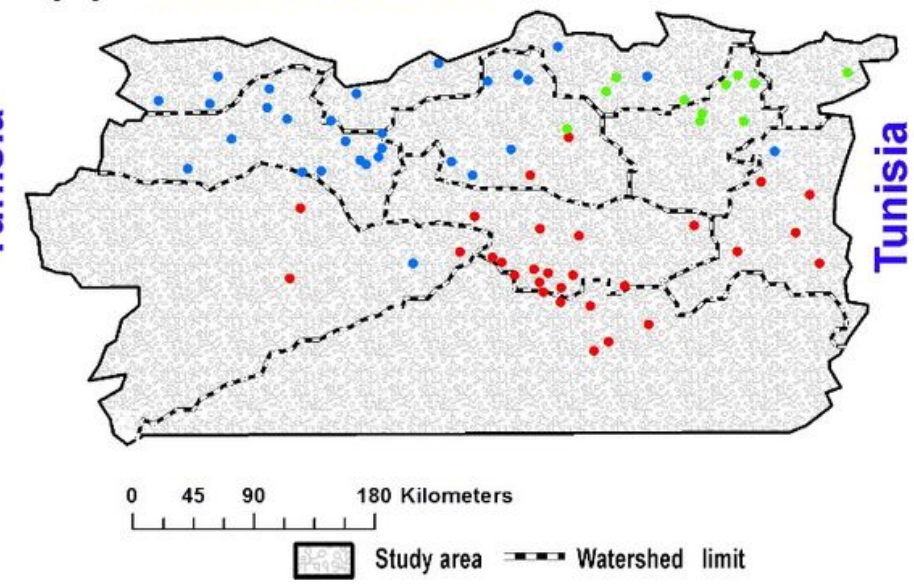

$-\frac{x}{2}-$

\section{(c) Mediterranean Sea}

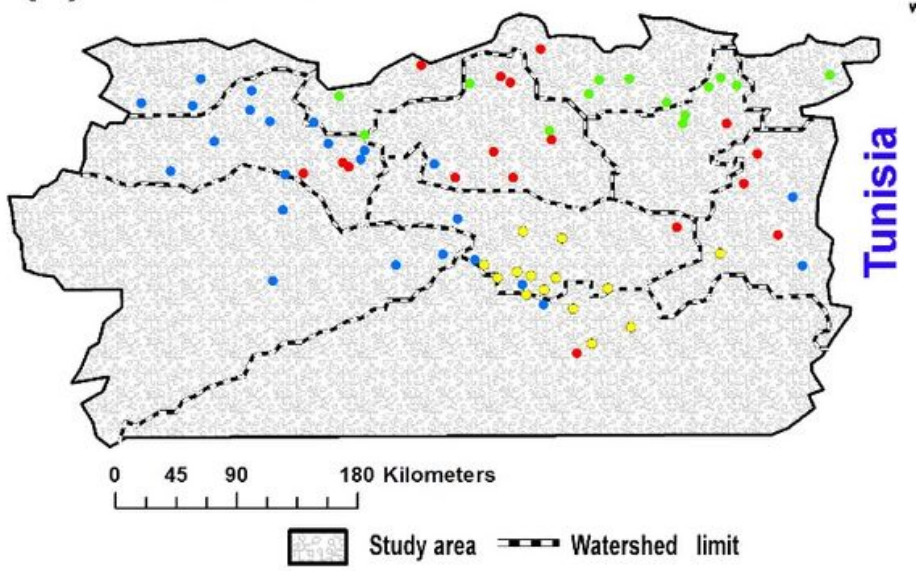

\section{Cluster 1 Cluster 3}

Figure 10 
Spatial distribution of the homogeneous groups obtained by applying the hierarchical ascending classification to the scale-average variances (trend components) of (a) 0.3-0.6 months, (b) 8-16 months and (c) 1-3 years. Note: The designations employed and the presentation of the material on this map do not imply the expression of any opinion whatsoever on the part of Research Square concerning the legal status of any country, territory, city or area or of its authorities, or concerning the delimitation of its frontiers or boundaries. This map has been provided by the authors.
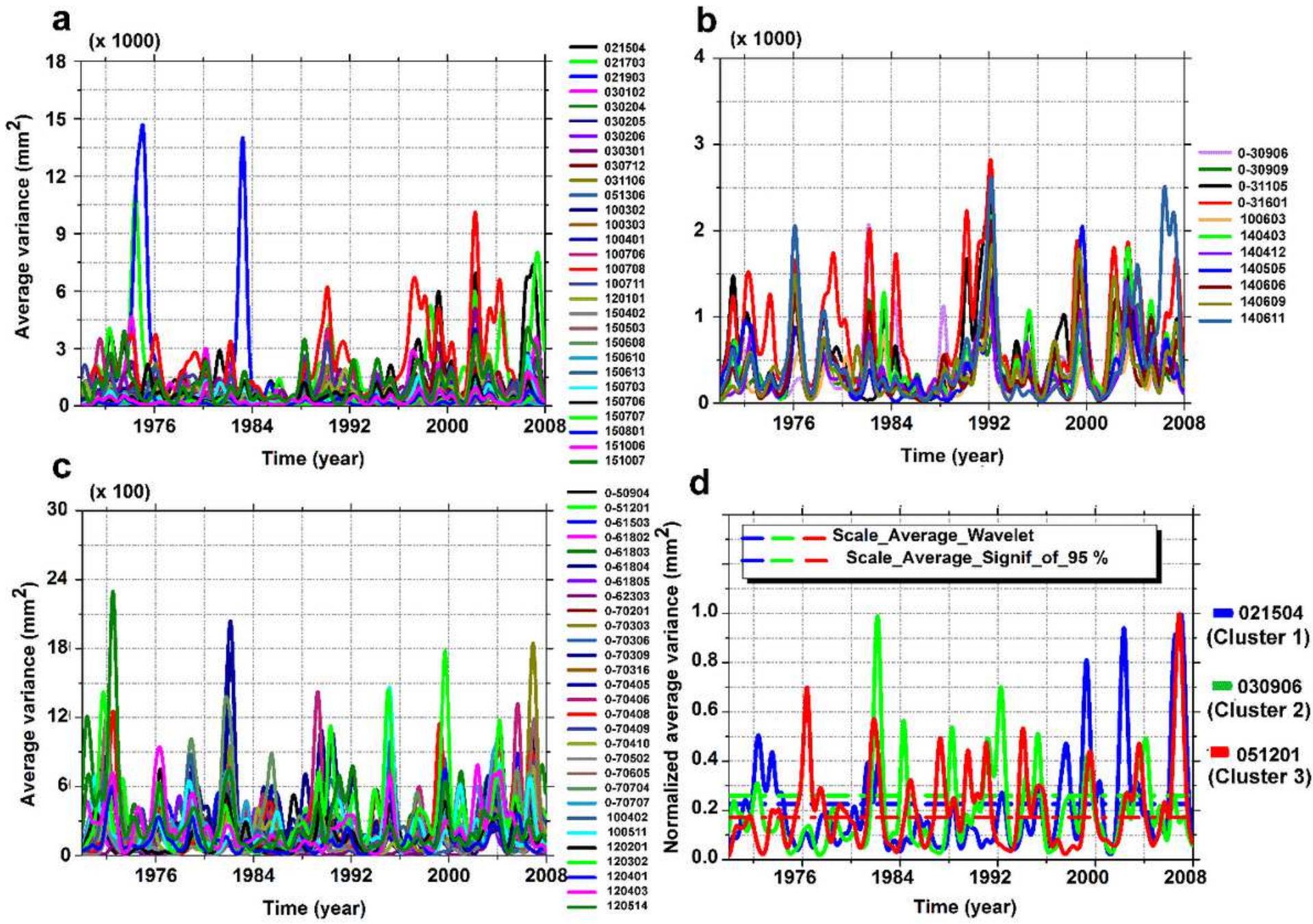

Figure 11

Evolution of the 0.3-0.6-month scale-average variance of the rainfall of (a) Cluster 1, (b) Cluster 2, (c) Cluster 3 , and (d) selected normalized spectra of the variance representative of each obtained cluster (the dashed red, blue and green lines represent the $95 \%$ confidence level). 

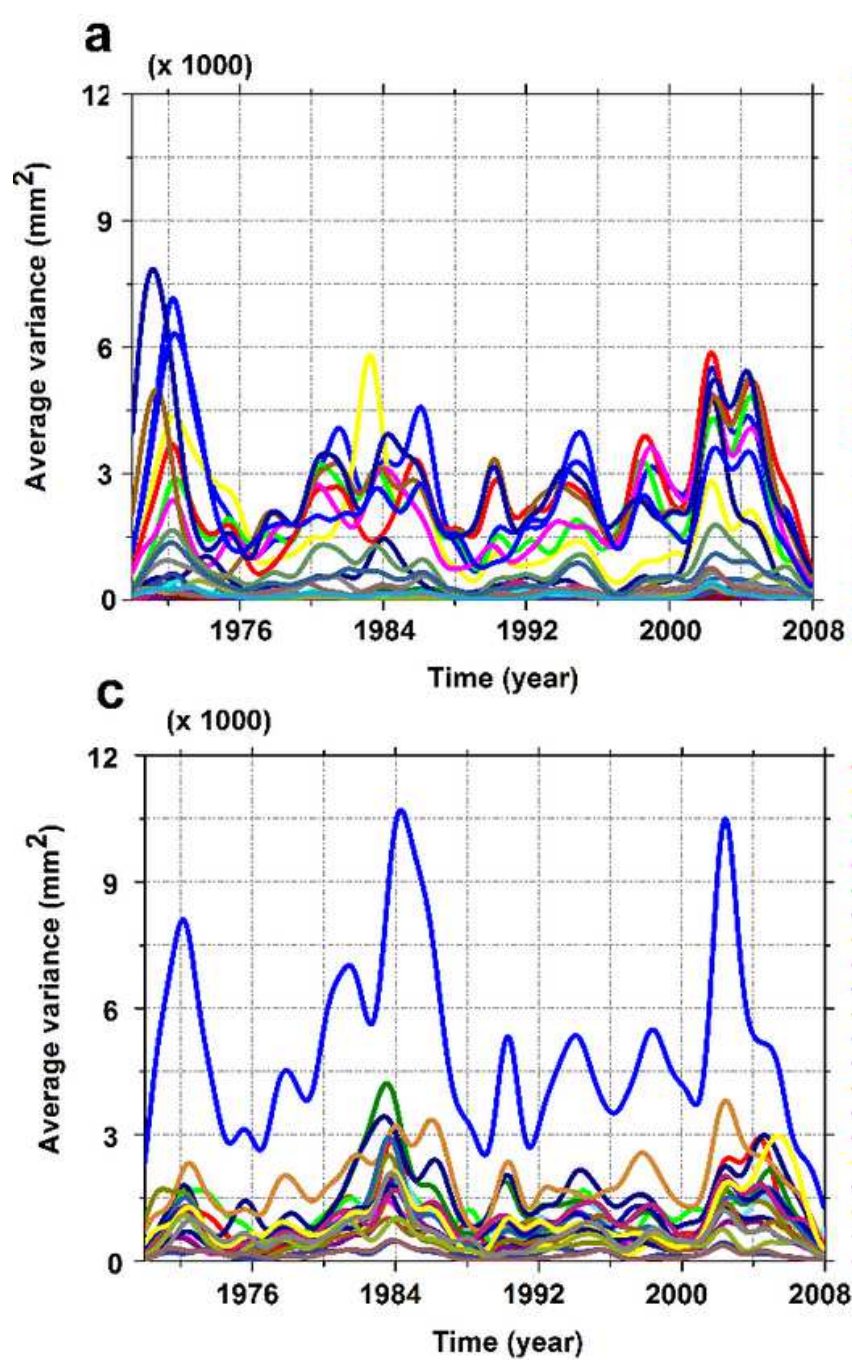

b

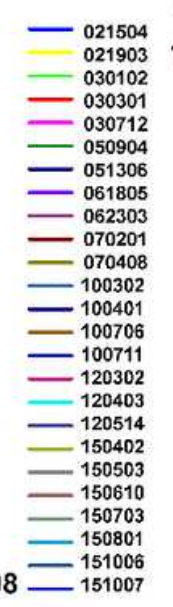

.
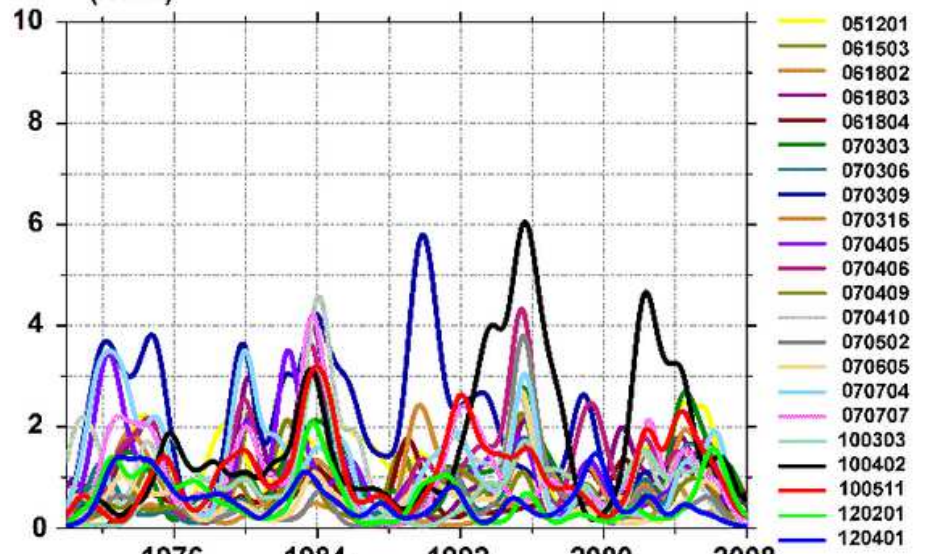

1976

1984

20002008

120401

d

Time (year)

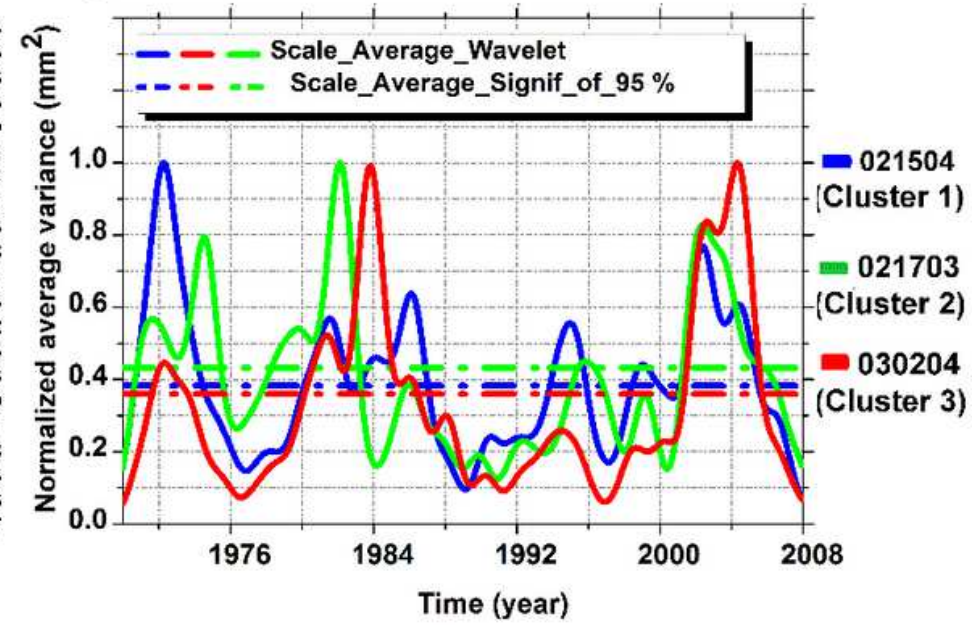

Figure 12

Evolution of the 8-16-month scale-average variance of the rainfall of (a) Cluster 1, (b) Cluster 2, (c) Cluster 3 , and (d) selected normalized spectra of the variance representative of each obtained cluster (the dashed red, blue and green lines represent the $95 \%$ confidence level). 

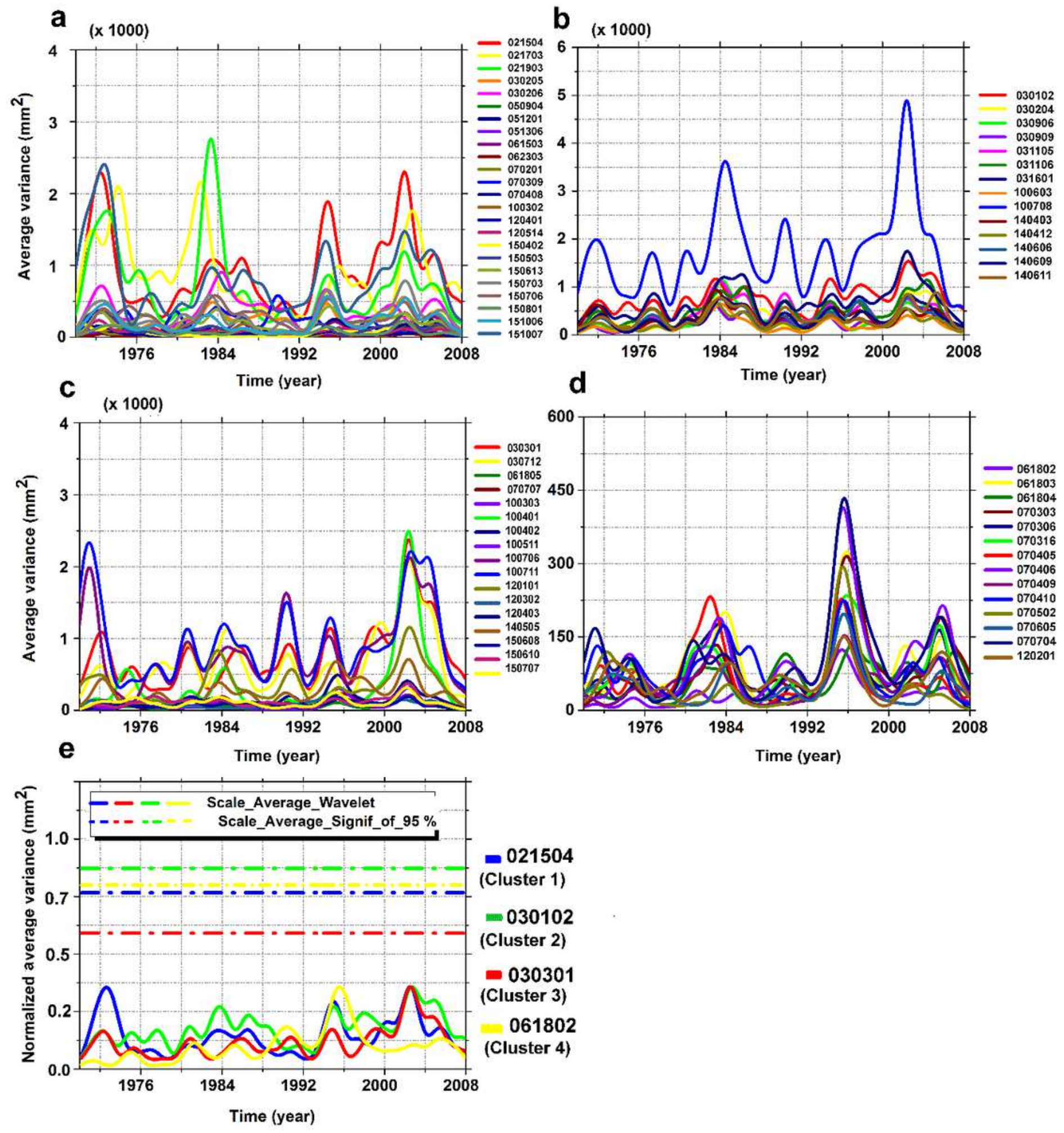

Figure 13

Evolution of the 1-3-year scale-average variance of the rainfall of (a) Cluster 1, (b) Cluster 2, (c) Cluster 3, (d) Cluster 4 and (e) selected normalized spectra of the variance representative of each obtained cluster (the dashed red, blue, green and yellow lines represent the 95\% confidence level). 